\title{
De NOUVEAUX OUTILS POUR L'ÉTUDE DES TRYPANOSOMOSES ANIMALES EN ZONE SOUDANIENNE : MODÉLISATION DE PAYSAGES ÉPIDÉMIOLOGIQUEMENT DANGEREUX PAR TÉLÉDÉTECTION et SYSTÈMES D'INFORMATION GÉOGRAPHIQUE
}

\author{
DE LA ROCQUE S.****, MICHEL J.F.****, DE WISPELAERE G.** \& CUISANCE D.*
}

Summary : NEW TOOLS FOR ANIMAL TRYPANOSOMOSIS STUDY: REMOTE SENSING AND GEOGRAPHICAL INFORMATION SYSTEM TO HIGHLIGHT THE SITES OF TRANSMISSION

Recent studies in a rangeland area of Burkina Faso showed that riparian tsetse flies (Glossina tachinoides and $G$. palpalis gambiensis) were found along the main rivers, but depending on their location, they had different hosts and were not infected by the same trypanosomoses. There were different epidemiological situations within a distance of a few kilometres, and local assessment of the trypanosome risk thus called for a global approach taking account of the environmental and human factors involved in the interfaces between hosts and vectors. Various types of information concerning entomology, parasitology, ecology, land occupation and animal production systems were fed into a

Geographical Information System. High spatial resolution remote sensing tools and original modelling methods were used to detect the valley landscapes most favourable to tsetse flies, and describe land use by herds. The impact of trypanosomes appeared to depend largely on animal movements, watering practices and the degree of contact with riparian tsetse flies. Linking these types of information revealed the most dangerous sites in epidemiological terms, which in this case represented some $18 \%$ of the network initially surveyed

KEY WORDS : Glossina, trypanosomosis, risk, remote sensing, Geographical Information System, West Africa.

\section{Résumé :}

Les études récentes menées dans une zone agro-pastorale du Burkina Faso ont montré que les glossines ripicoles (Glossina tachinoides et $G$. palpalis gambiensis/ sont présentes le long du réseau hydrographique principal, mais selon leur localisation, leurs hôtes nourriciers sont différents et elles ne sont pas infectées par les mêmes trypanosomes. Différentes situations épidémiologiques se côtoient à l'échelle de quelques kilomètres, et l'appréciation locale du risque trypanosomien nécessite une approche globale prenant en compte les facteurs

environnementaux et anthropiques qui interviennent dans les interfaces entre les hôtes et les vecteurs. Ces différentes informations, concernant l'entomologie, la parasitologie, l'écologie, l'occupation du sol ou encore les systèmes d'élevage ont été intégrées dans un Système d'Information Géographique. Des outils de télédétection à haute résolution spatiale et des méthodes originales de modélisation ont été utilisés pour, d'une part, mettre en évidence les paysages de vallées les plus favorables aux glossines, d'autre part, décrire l'utilisation de l'espace par les troupeaux. L'incidence trypanosomienne apparait largement dépendante des parcours des animaux, de leur pratique d'abreuvement et de leur contact avec les glossines ripicoles. Le croisement de ces informations permet de révéler les sites épidémiologiquement les plus dangereux, qui représentent finalement environ $18 \%$ du réseau initialement prospecté.

MOTS CLÉS : glossines, trypanosomoses, risque parasitaire, télédétection Systèmes d'Information Géographique, Afrique de l'Ouest.

sentes, principalement Glossina tachinoides et Glossina palpalis gambiensis, ont pour habitat les galeries forestières situées le long des cours d'eau. La lutte contre ces vecteurs repose essentiellement sur la pose de pièges ou d'écrans imprégnés et d'applications épicutanées de formulations insecticides sur le bétail (Laveissière \& Couret, 1980, Cuisance et al., 1994). Les méthodes sont simples, écologiquement satisfaisantes, et peuvent être appliquées de manière locale pour contrôler les densités de vecteurs et arrêter les cycles parasitaires. Afin que la lutte soit supportable à la fois techniquement et financièrement par les populations rurales, elle doit pourtant être ciblée autour des sites majeurs de transmission.

Depuis une vingtaine d'années, l'Afrique occidentale subit une forte pression démographique, et ses paysages naturels, économiques et sociaux se transforment.

\footnotetext{
* CIRAD-EMVT, campus de Baillarguet, TA 30 F, 34398 Montpellier Cedex 5, France.

** CIRDES, BP 454, 01 Bobo Dioulasso, Burkina Faso.

Correspondance : Stéphane de La Rocque.

Tél. : (226) 973687 - Fax : (226) 972320

E-mail : stephane.delarocque@cirad.fr
} 
Avec l'augmentation des surfaces cultivées, les habitats naturels des glossines s'éclaircissent et se fragmentent (de La Rocque et al., 2001a). Certaines espèces de tsé-tsé sont pourtant capables de s'adapter à des milieux anthropisés, et créent alors de nouveaux sites de transmission souvent proches des hommes (Laveissière et al., 1986).

Les sites épidémiologiquement dangereux se situent aux points d'interfaces les plus intenses dans l'espace et dans le temps entre les vecteurs et les hôtes. Pour orienter leurs stratégies d'interventions, les décideurs attendent le développement d'outils et de méthodes pour repérer rapidement ces zones de transmission (FAO, 1994, Hendrickx et al., 2001). Néanmoins, le développement de tels outils suppose, d'une part de bien décrire le fonctionnement du système pathogène dans chaque environnement et, d'autre part, de mettre en évidence des indicateurs simples, facilement appréhendés par une procédure rapide et standardisée. Ces objectifs ont guidé la présente étude, réalisée avec des spécialistes de disciplines variées et combinant au sein d'un Système d'Information Géographique (SIG) des données de natures diverses, issues du terrain, de modèles et de télédétection (de La Rocque et al., 2001b, sous presse).

\section{LOCALISATION DE L'ÉTUDE}

La zone agropastorale de Sidéradougou se situe au Burkina Faso, au sud de la ville de Bobo Dioulasso $\left(11^{\circ}\right.$ $10 \mathrm{~N}, 4^{\circ} 19 \mathrm{~W}$ ) (fig. 1). Elle reçoit 1000 à $1100 \mathrm{~mm}$ de précipitations par an, et connaît une saison sèche de novembre à mars, une saison humide de juin à septembre et deux périodes de transition. La zone d'étude s'étend au pied de la falaise de Banfora et est représentative du domaine tropical soudanien, avec des savanes arborées à "karité" (Vitelaria paradoxa) et à Terminalia laxiflora. Des formations ripicoles arbustives ou des galeries forestières occupent les berges du réseau hydrographique. La principale rivière est la Koba, qui prend sa source au pied de la falaise de Banfora et a pour affluent principal le Tolé.

La zone de Sidéradougou a été choisie comme site d'étude en raison de l'abondance de données anciennes disponibles. Dans les années 80, elle fut en effet proposée comme zone d'accueil pour les éleveurs transhumants en saison sèche, et ses ressources avaient alors été évaluées (Toutain et al., 1978). Malgré cette vocation pastorale, la zone est soumise depuis une dizaine d'années à une pression humaine croissante, due à ses potentialités agricoles en particulier pour la culture cotonnière. La dynamique d'occupation des terres suit un "front pionnier" orienté nord-est/sudouest, créé par l'arrivée d'agriculteurs Mossi originaires du plateau central du pays (fig. 2) (Augusseau et al., 1998). La zone de Sidéradougou rassemble ainsi des situations agro-écologiques contrastées : l'occupation agricole est particulièrement marquée dans sa partie orientale (partie dite agricole), la partie au sud, au contraire, est essentiellement occupée par des savanes arborées denses (partie pastorale) et la partie ouest est intermédiaire (partie agro-pastorale), avec des savanes arborées lâches et des champs dispersés (respectivement $38 \%, 7 \%$ et $18 \%$ de surfaces cultivées).

\section{SITUATION ENTOMOLOGIQUE ET PARASITOLOGIQUE}

\section{ENQUÊTE ENTOMOLOGIQUE}

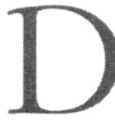
es enquêtes entomologiques menées dans les années 80 avaient révélé la présence de trois espèces de glossines dans la zone, deux localisées dans les galeries forestières le long des cours d'eau (Glossina tachinoides Westwood et Glossina palpalis gambiensis Vanderplank), une dans les savanes (Glossina morsitans submorsitans Newstead) (Cuisance et al., 1984). Afin d'actualiser ces données, une nouvelle enquête entomologique a été réalisée dans la zone durant la saison sèche 1996. Près de 120 km de réseau hydrographique ont été prospectés de janvier à juin 1996 (de La Rocque, 1997). Des pièges biconiques (Challier \& Laveissiere, 1973) ont été disposés de manière systématique tous les 100 mètres, et laissés en place une journée. La localisation géographique des pièges a été relevée à l'aide de récepteurs GPS (Global Positioning System). Pour éviter l'impact des variations saisonnières, l'ordre de prospection a été établi de manière aléatoire.

Au total, lors de cette campagne, 1026 pièges ont été posés, et ont capturé 3604 glossines, appartenant aux deux espèces ripicoles (1512 G. palpalis gambiensis et 2092 G. tachinoides). Aucune G. morsitans submorsitans n'a été attrapée. 1802 individus ont été disséquées (768 G. p. gambiensis et 1034 G. tachinoides) pour rechercher les trypanosomes dans les pièces buccales (labre et hypopharynx), l'intestin moyen et des glandes salivaires. Lorsque le sang résiduel de l'intestin était suffisamment abondant, il a été récolté sur papier filtre pour une identification ultérieure de l'hôte nourricier par test ELISA (Clausen et al., 1998). Les organes infectés ont été conservés dans l'eau stérile pour des caractérisations par amplification d'ADN (Polymerase Chain Reaction) au laboratoire (Solano et al., 1996; Reifenberg et al., 1997).

- Répartition spatiale des glossines

La répartition de chacune des deux espèces de glossines capturées dans la zone est illustrée dans la figure 3. Glossina tachinoides est capturée sur l'ensemble du réseau 

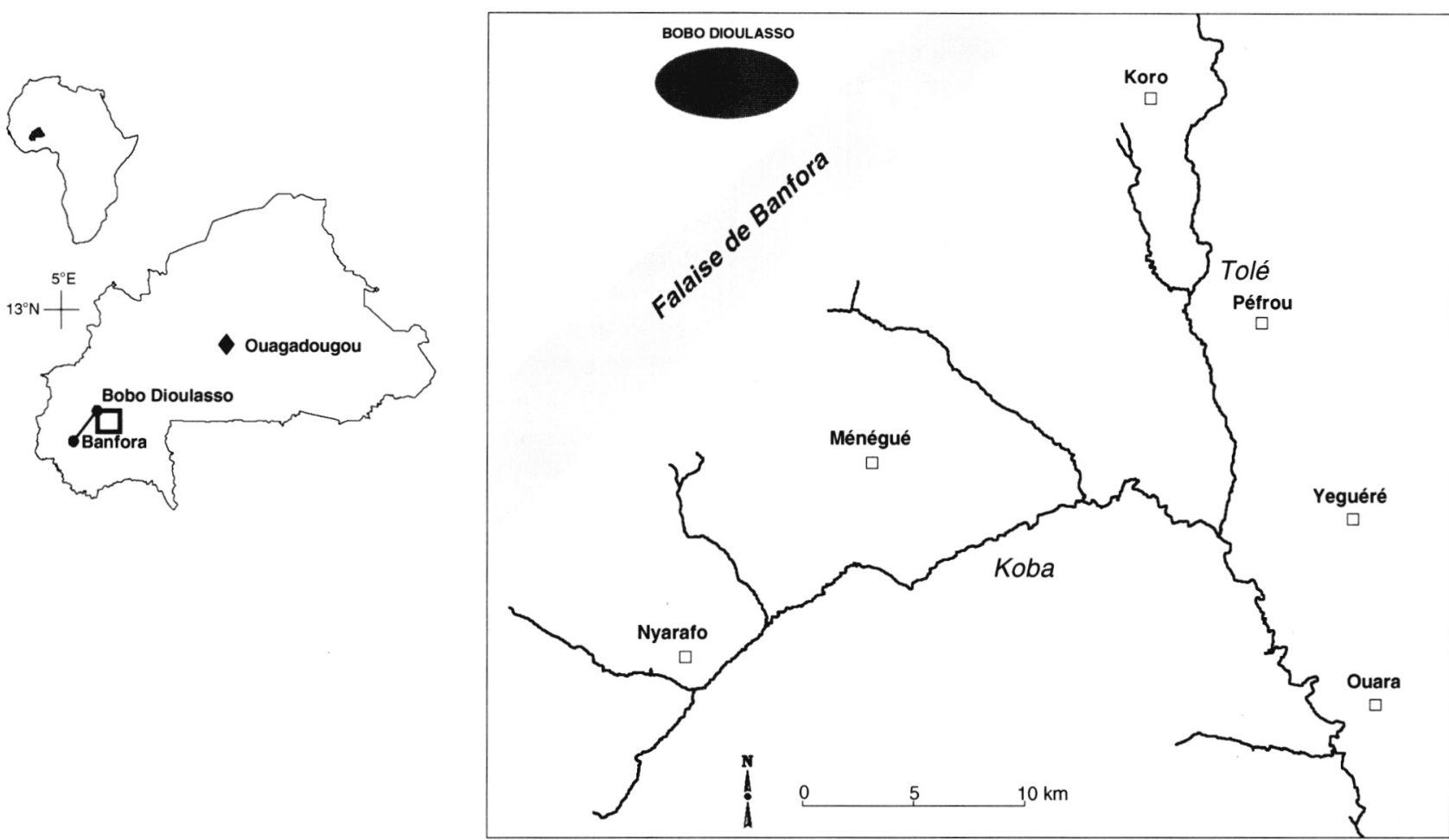

Fig. 1. - Localisation de la zone de Sidéradougou, Burkina Faso.

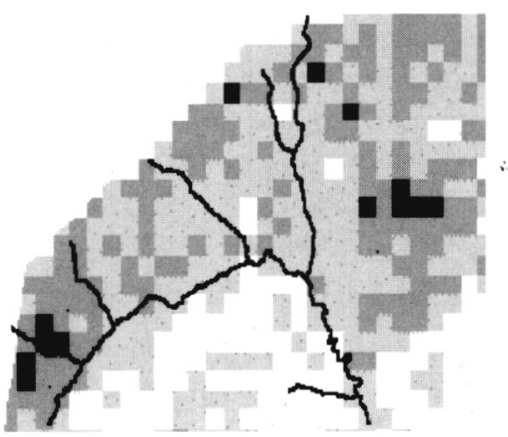

1976

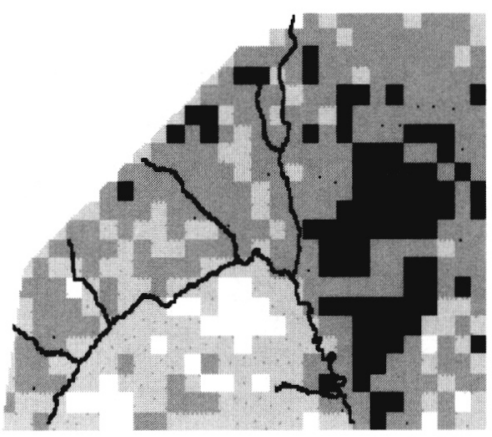

1991

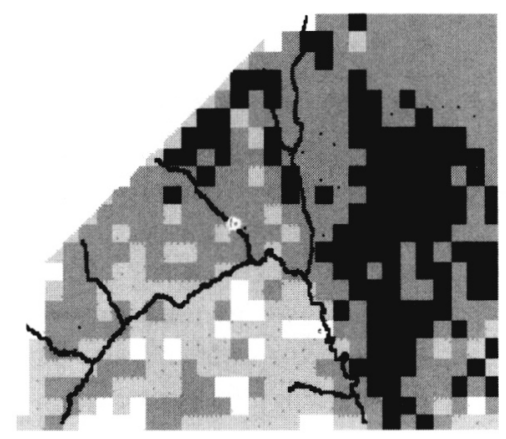

1996

Densité agricole
: nulle
: moins de $10 \%$
$\square:$ de 10 à $30 \%$
: plus de $30 \%$

Fig 2. - Évolution de l'occupation agricole entre 1976 et 1996 dans la zone de Sidéradougou.

Évaluation à partir d'images de télédétection de différentes dates (LANDSAT MSS, mars 1976, résolution : $57 \times 79$ mètres, SPOT, décembre 1991 et 1996, résolution : $20 \times 20$ mètres). Le parcellaire agricole a été cartographié directement sur les images satellites brutes, numérisé puis agrégé à l'intérieur d'une trame dont la maille élémentaire représente 400 hectares. 

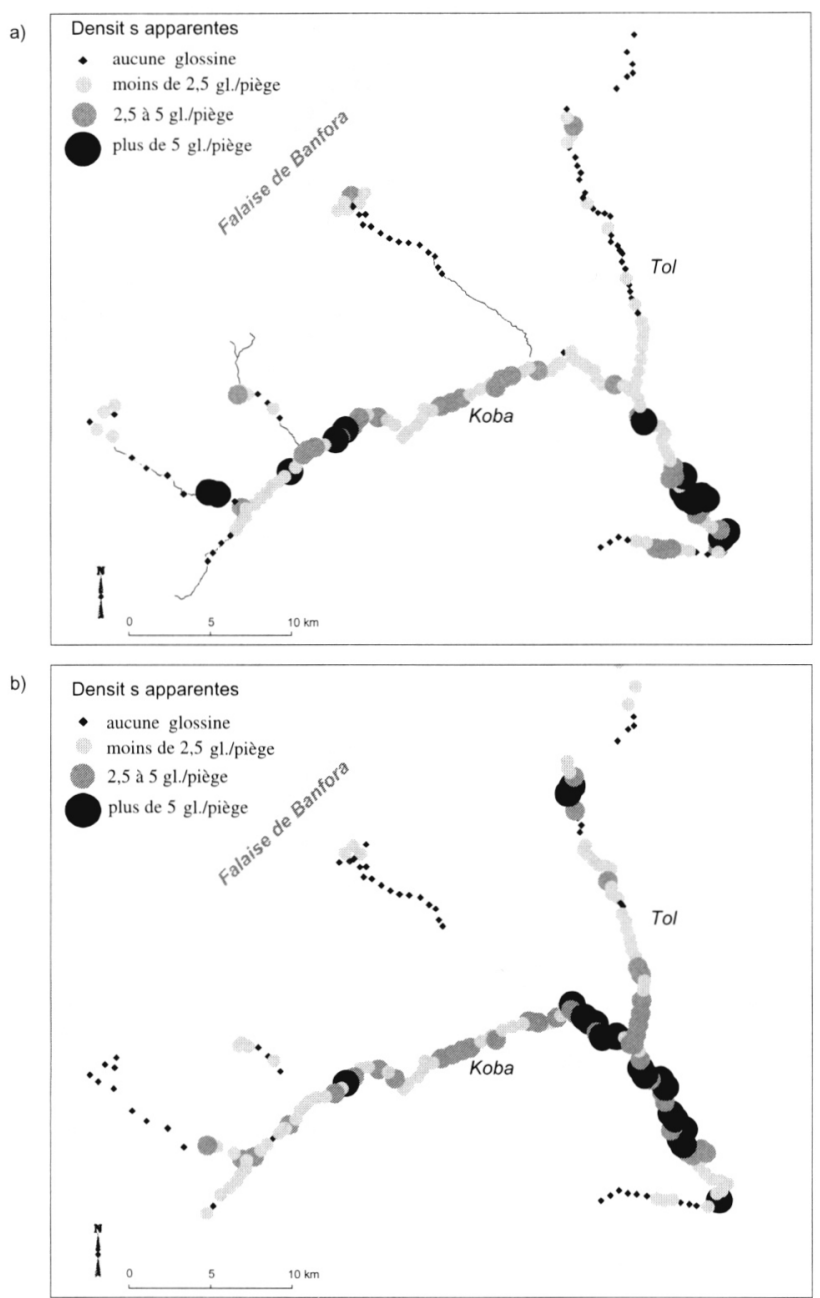

Fig. 3. - Répartition actuelle de Glossina palpalis gambiensis (a) et Glossina tachinoides (b) dans la zone d'étude (chaque symbole représente une moyenne des captures journalières sur cinq pièges).

hydrographique, mais G. p. gambiensis ne se localise que sur le cours d'eau majeur (Koba). Les plus fortes densités de glossines (plus de cinq insectes par piège et par jour) sont observées le long de la branche aval de la rivière Koba, où les galeries forestières sont souvent larges. Au niveau des sources au pied de la falaise, les petites formations boisées abritent les deux espèces en densités moyennes.
- Infection parasitaire des glossines

Sur les 1802 glossines disséquées, 298 ont été trouvées infectées par des trypanosomes. Aucune différence statistique n'a été mise en évidence entre les taux d'infection, tous organes confondus, de ces deux espèces (respectivement 14,4 et $12,6 \%$ chez G. tachinoides et G. p. gambiensis). Mais si les infections conjointes des pièces buccales et de l'intestin sont en proportion comparables, celles du seul tube digestif sont plus fréquentes chez G. p. gambiensis (69\% contre $39 \%$, p < 0,001), et inversement celles du proboscis seul sont plus abondantes chez G. tachinoides ( $46 \%$ contre $21 \%, \mathrm{p}<0,001$ ).

Le taux d'identification a été moins élevé chez $G$. $p$. gambiensis (28,9\%) que chez G. tachinoides (63,8\%) (tableau I). Les infections du tube digestif seul sont plus rarement identifiées $(18,2 \%)$ que celles du proboscis seul $(87,9 \%)$ ou celles à la fois du proboscis et de l'intestin $(72,7 \%)(\mathrm{p}<0,001)$. En particulier pour $G$. $p$. gambiensis les taux d'identification des trypanosomes localisés dans le seul tube digestif sont très faibles (8,4\%, contre $24,6 \%$ pour G. tachinoides). Pour les deux espèces de glossines, Trypanosoma vivax a été le parasite le plus fréquemment reconnu. Des infections mixtes ont été souvent observées chez $G$. tachinoides (16,4\%) plus rarement chez G. p. gambiensis (4,1\%). En particulier $T$. congolense type "forêt" était dans $84,2 \%$ des cas associé à un autre trypanosome.

Il y a donc un grand nombre d'infections qui ne peuvent être identifiées, notamment lorsqu'elles se localisent dans le tube digestif. Les amorces disponibles actuellement (McNamara et al., 1995; Solano et al., 1995; Reifenberg, 1996) sont considérées spécifiques des différents trypanosomes pathogènes circulant dans la sous-région, et les infections non identifiées sont attribuées à des parasites de reptiles tels que T. grayilike ou T. varani, qu'aucune amorce ne permet de caractériser (D'Amico, 1993).

\section{SITUATION PARASITAIRE DU BÉTAIL}

- Enquête de prévalence parasitaire et sérologique

L'ensemble du cheptel de la zone est estimé à 16000 têtes (Michel et al., 1999). Une enquête de prévalence

\begin{tabular}{|c|c|c|c|c|c|}
\hline & $\begin{array}{c}\text { Taux } \\
\text { d'identification }\end{array}$ & T. vivax & $\begin{array}{l}T . \text { congo. } \\
\text { "savane" }\end{array}$ & $\begin{array}{l}\text { T. congo. } \\
\text { "forêt" }\end{array}$ & T. brucei \\
\hline G.p. gambiensis $(\mathrm{n}=121)$ & 28,9 & 18,2 & 8,3 & 4,1 & 2,5 \\
\hline \multirow[t]{2}{*}{ G. tachinoides $(\mathrm{n}=177)$} & 63,8 & 46,9 & 20,3 & 7,9 & 9,6 \\
\hline & **** & $* * *$ & $* *$ & $\circ$ & $*$ \\
\hline
\end{tabular}

Test du Khi ${ }^{2}$ significatif à : ${ }^{* * *}, 0,1 \% ;{ }^{* *}, 1 \% ;{ }^{*}, 5 \% ;^{\circ}$ : non significatif.

Le pourcentage d'identification total est inférieur à la somme des résultats par espèce en raison des infections mixtes.

Tableau I. - Taux d'identification des trypanosomes et résultats des analyses par PCR (en pourcentage) chez G. tachinoides et G. p. Gambiensis. 
parasitologique et sérologique a été réalisée en novembre 1997, sur un échantillon de 1035 bovins répartis dans 125 troupeaux. Les troupeaux ont été sélectionnés selon leur localisation géographique (partie agricole, agro-pastorale ou pastorale de la zone) et leur système d'élevage (élevage traditionnel extensif, élevage à vocation culturale avec dominance d'animaux de trait).

Le diagnostic parasitologique a été réalisé par examen microscopique de la phase leucocytaire après centrifugation en tube microcapillaire (Murray et al., 1977), technique reconnue sensible pour des parasitémies à partir de 300 à 700 trypanosomes/ml (Uilenberg, 1998). L'observation directe des trypanosomes, leur taille, leur morphologie, leur mobilité et leur motilité permettent dans bon nombre de cas de réaliser une diagnose d'espèce (Chartier et al., 2000), mais des analyses complémentaires par PCR ont confirmé les cas douteux (Solano et al., 1999). Des recherches d'anticorps ont été réalisées par ELISA-indirects, interprétés selon la méthode des seuils de positivité (Desquesnes et al., 1999).

La prévalence parasitologique s'est révélée être de $11,5 \%( \pm 3,9)$, l'hématocrite moyen de 30,5\% $( \pm 5,4)$ et la prévalence sérologique de $81,7 \%( \pm 2,4)$, ce qui confirme la situation enzootique de la trypanosomose animale dans la zone.

- Modélisation de la prévalence pour l'ensemble de la zone

Une modélisation de la prévalence parasitaire et de la séroprévalence observées lors de l'enquête a été effectuée par régression logistique. Le modèle obtenu a été appliqué à l'ensemble de la zone, en s'appuyant sur les données d'un recensement exhaustif des exploitations d'élevage (Michel, soumis). Ces résultats confirment que dans cette zone où seules des glossines ripicoles sont présentes, la trypanosomose animale est centrée sur le réseau hydrographique (fig. 4). Le modèle obtenu permet également d'identifier et de quantifier les paramètres associés au risque d'infection; il est apparu en effet que la proximité du réseau hydrographique (moins de $2 \mathrm{~km}$ ) entraîne pour les animaux une augmentation d'un facteur 4 du risque d'infection. Ces résultats sont confirmés par les observations effectuées sur le terrain lors de suivis de troupeaux sentinelles.

\section{FONCTIONNEMENT DE LA TRANSMISSION} ET ÉVALUATION DU RISQUE

- Des bovins plus ou moins infectés selon les pratiques

Deux groupes d'animaux sentinelles, appartenant à des systèmes d'élevages contrastés, ont été suivis durant deux ans (de La Rocque et al., 1999). Le premier est
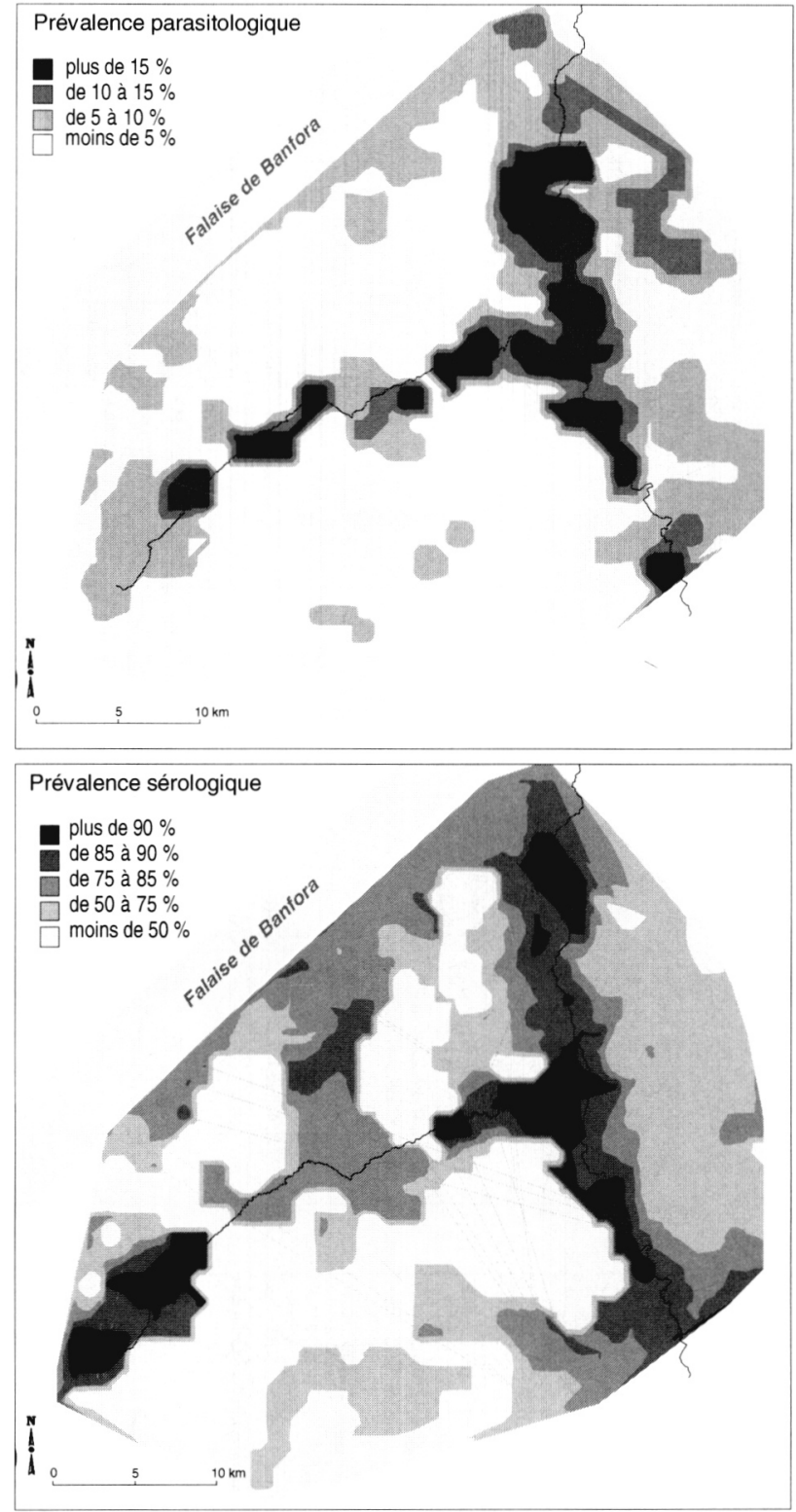

Fig. 4. - Prévalences parasitologiques et sérologiques estimées dans la zone de Sidéradougou.

détenu par des éleveurs Peuhl, localisés dans la partie pastorale au sud-ouest de la zone (village de Nakaka) (fig. 1). Le second est constitué d'animaux appartenant à plusieurs agriculteurs d'ethnie Bobo installés dans une zone fortement occupée par l'agriculture (terroir de Péfrou). Des prélèvements sanguins ont été réalisés toutes les cinq semaines, selon un protocole de suivi qui s'apparente à celui dit de "l'Index Bérénil" (du nom du trypanocide usuellement employé) permettant d'estimer l'incidence trypanosomienne. Les troupeaux ont été suivis à différentes périodes de l'année pour décrire leurs parcours journaliers. Afin d'estimer la dispersion des glossines dans les savanes en saison pluvieuse, des pièges biconiques et monoconiques du 

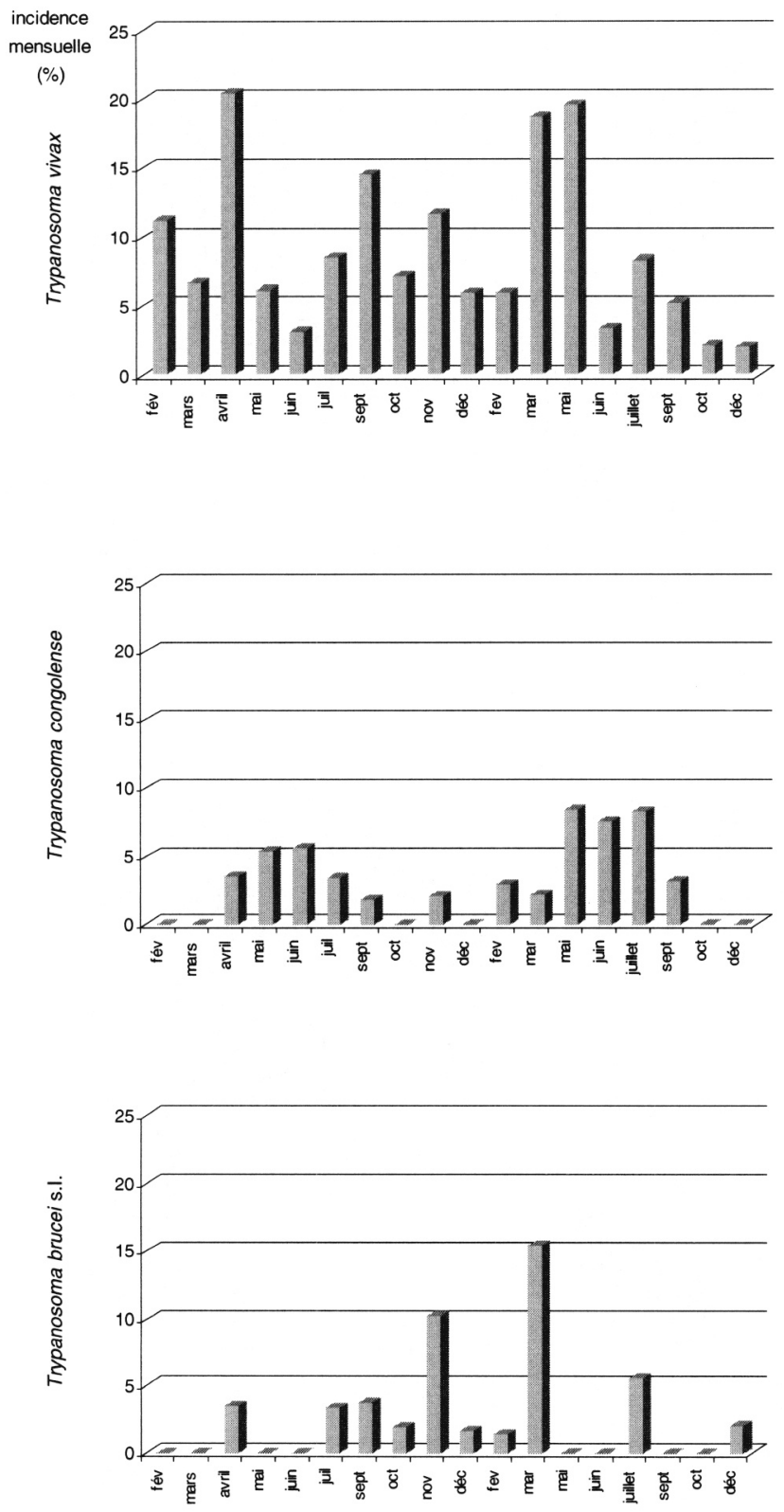

Fig. 5. - Incidences trypanosomiennes mensuelles (Trypanosoma vivax, T. congolense, T.brucei s.l.) observées dans le troupeau du village de Nakaka (de La Rocque et al., 1999).

type Vavoua ont été disposés alternativement tous les 100 mètres le long de transects allant du point d'abreuvement le plus proche jusqu'au village, toutes les deux semaines de juillet à septembre.

La figure 5 présente les incidences mensuelles observées dans le troupeau de Nakaka durant les deux années de suivi ( 55 animaux). Les incidences mensuelles de l'infection à T.vivax se situent pratiquement toute l'année entre 5 et $10 \%$, avec des pics jusqu'à $20 \%$ en saison sèche chaude. Celles de T. congolense sont centrées sur la fin de saison sèche chaude et la saison des pluies, période où les densités de glossines sont élevées. Les parcours des animaux en fin de saison sèche (juillet) et durant la saison des pluies (septembre) sont représentés sur la figure 6.

Chez les Peuhl, les animaux sont généralement confiés à un jeune bouvier. Au mois de juillet, période de la préparation des cultures, ils doivent éviter les aires cultivées et leurs déplacements sont orientés vers un site d'abreuvement, généralement au niveau d'un point d'eau pérenne du réseau hydrographique (Landais, 1983; Lhoste et al., 1993). Au mois de septembre, les pluies ont créé de nombreuses mares temporaires, l'espace pastoral se libère après les premières récoltes et les animaux pénètrent dans les champs pour profiter des résidus de cultures. Les parcours sont alors plus restreints et centrés autour du campement. La dispersion des mouches dans les savanes est maximale durant la saison des pluies. Lors du suivi entomologique, Glossina tachinoides a été capturée régulièrement à différents niveaux du transect de piège, et jusque dans le village de Nakaka pourtant distant de deux kilomètres du réseau hydrographique (fig. 6). Cette dispersion est favorisée par la situation du village, localisé le long d'une dépression humide où la végétation arborée est dense.

Ainsi, à Nakaka, les animaux sont en permanence soumis à une pression parasitaire. En saison sèche, la transmission des trypanosomes est assurée par un contact étroit et régulier entre les bovins et les glossines au niveau des points d'abreuvement situés dans la galerie. En saison des pluies, les bovins ne fréquentent plus le réseau hydrographique mais les mouches se dispersent dans les savanes et peuvent infecter les animaux jusque dans le village.

Les résultats parasitologiques obtenus à Péfrou indiquent deux situations très différentes selon la proximité entre le campement du propriétaire des bovins et le réseau hydrographique. Les courbes d'incidences obtenues chez les animaux des campements localisés à moins de 500 mètres du Tolé sont reportées sur la figure 7 (neuf éleveurs, 33 animaux). Elles indiquent une pression de transmission parasitaire régulière tout le long de l'année, essentiellement à $T$. vivax et à T. congolense, en rapport avec une fréquentation régulière des puisards creusés dans le lit de la rivière (fig. 8). Dans les troupeaux des campements situés à plus de deux kilomètres du réseau hydrographique (11 éleveurs, 41 animaux), les résultats parasitologiques obtenus indiquent que la transmission est exceptionnelle, et les quelques infections détectées surviennent durant les périodes humides (fig. 9). Ces animaux ne fréquentent jamais le réseau hydrographique, les effectifs réduits des troupeaux permettant aux propriétaires de les abreuver avec l'eau du puits familial (fig. 8). Par ailleurs, les glossines ne se dispersent pas ou peu dans les savanes densément occupées par l'agriculture. 
densités de Glossina tachinoides

O aucune glossine

0 de 1 à 3 glossines

- de 3 à 6 glossines

- de 6 à 30 glossines

\section{...... parcours de fin de saison sèche \\ \#\# parcours de saison des pluies \\ réseau hydrographique}

savane arborée dense

parcelles cultivées

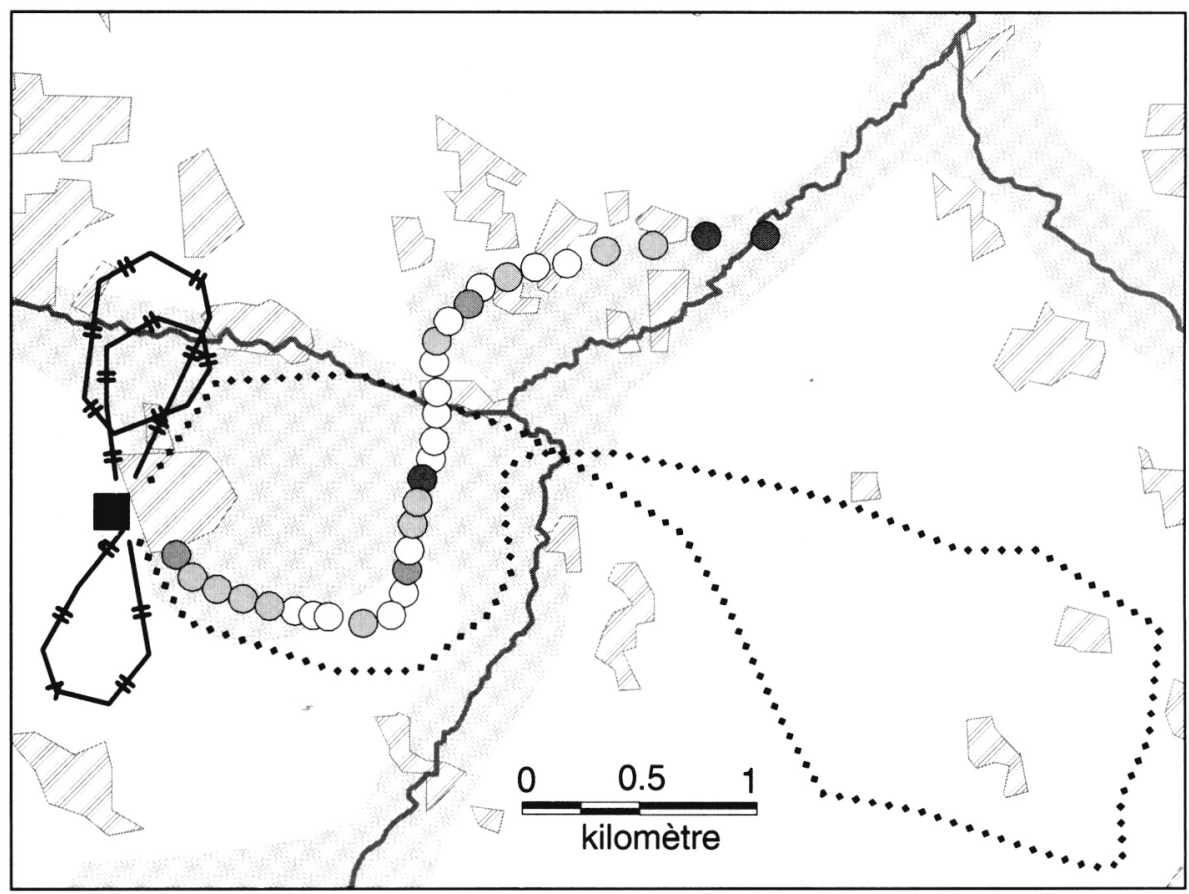

Fig. 6. - Parcours des animaux du village de Nakaka en fin de saison sèche et en saison des pluies et résultats entomologiques le long du transect (de La Rocque et al., 1999).
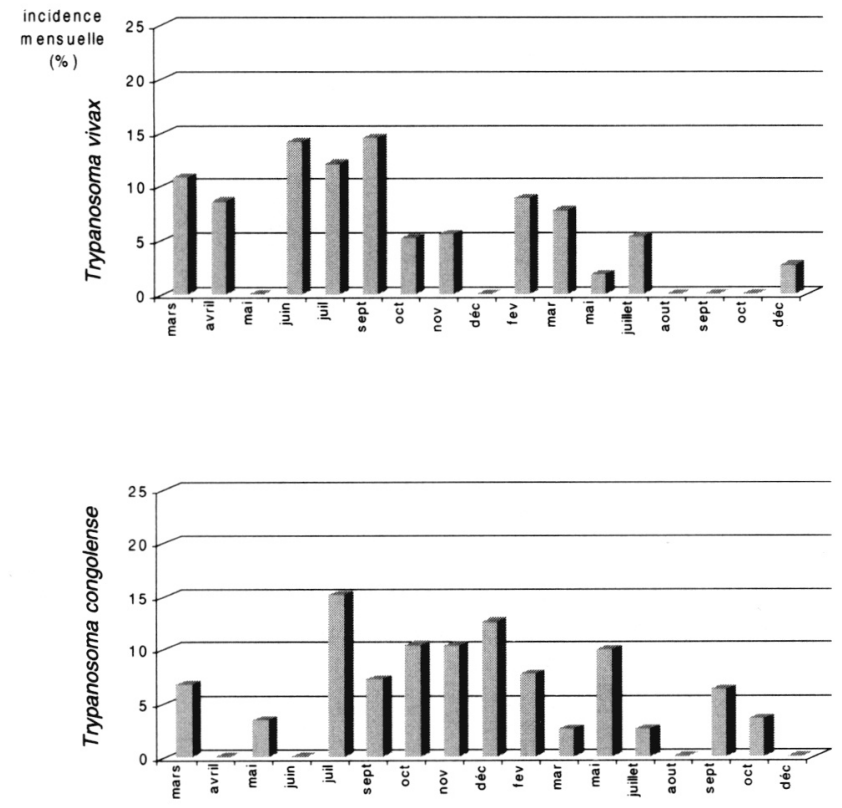

Fig. 7. - Incidences trypanosomiennes mensuelles (Trypanosoma vivax, T. congolense, T.brucei s.l.) observées chez les animaux du village de Péfrou issus de campements proches de la rivière (de La Rocque et al., 1999).

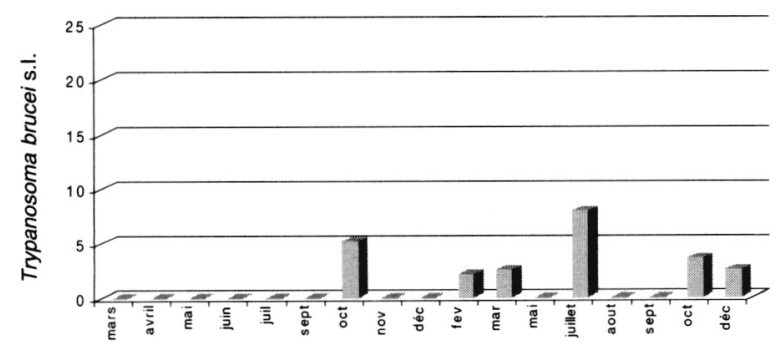




\section{DE LA ROCQUE S., MICHEL J.F., DE WISPELAERE G. \& CUISANCE D.}

densités de Glossina tachinoides

aucune glossine

0 de 1 à 3 glossines

de 3 à 6 glossines

- de 6 à 30 glossines

- campements qui abreuvent leurs animaux à la rivière

$\Phi$ campements qui abreuvent leurs animaux à leur puits

réseau hydrographique

savane arborée dense

parcelles cultivées

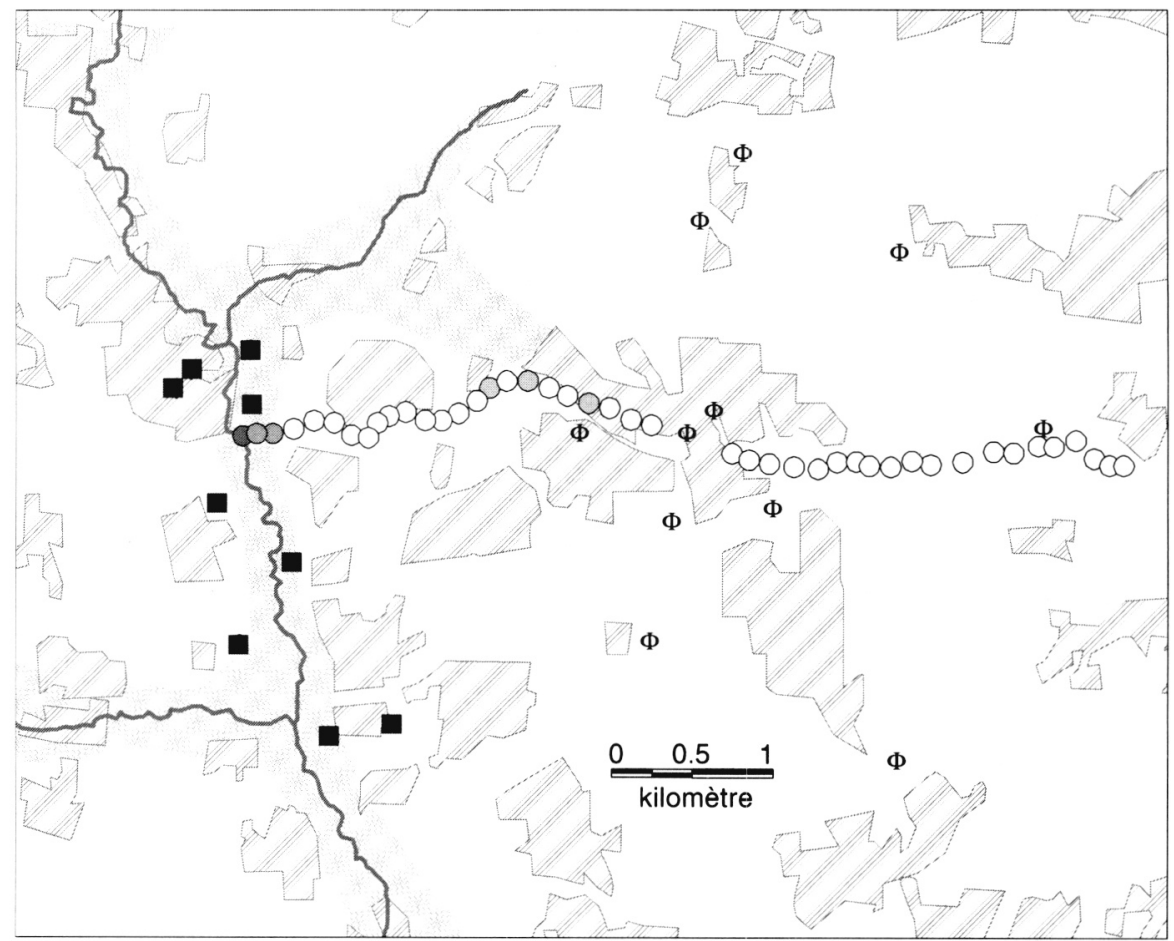

Fig. 8. - Localisation des campements de Péfrou et résultats entomologiques le long du transect (de La Rocque et al., 1999).
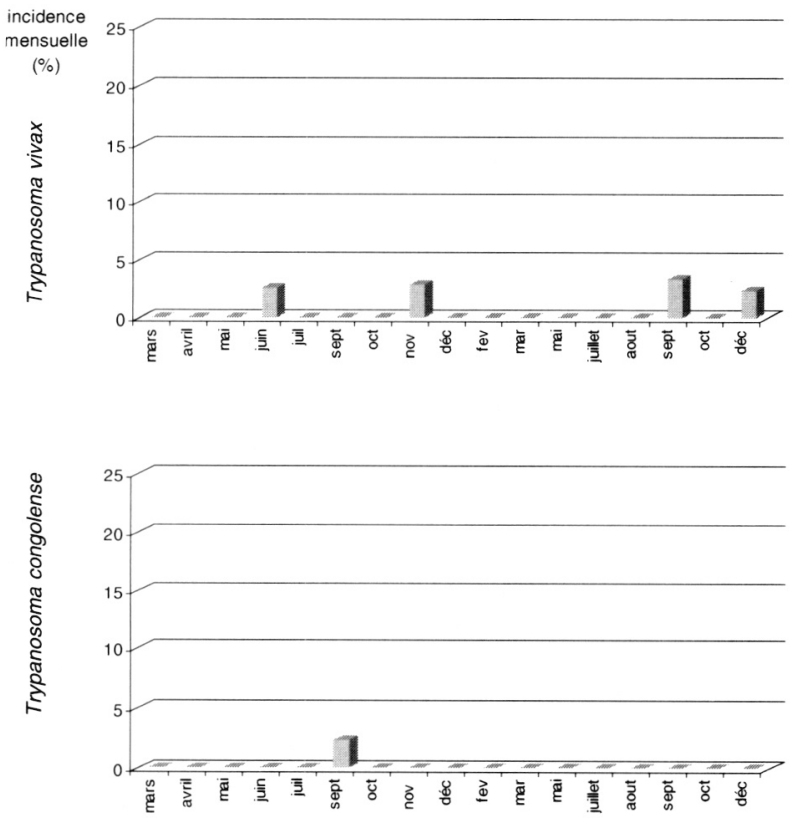

Fig. 9. - Incidences trypanosomiennes mensuelles (Trypanosoma vivax, T. congolense, T.brucei s.1.) observées chez les animaux du village de Péfrou issus de campements éloignés de la rivière (de La Rocque et al., 1999).

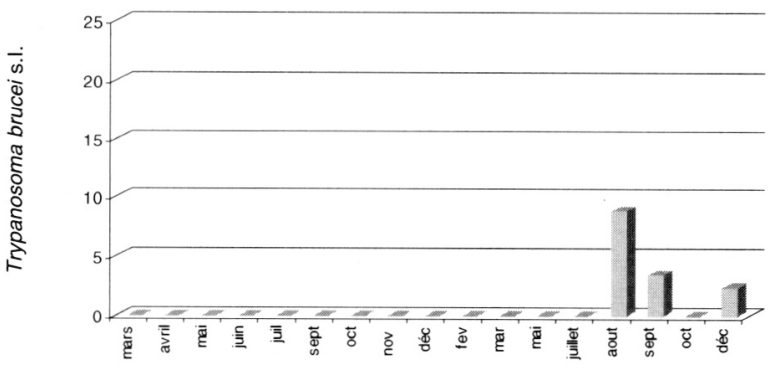


Ces résultats révèlent la diversité des situations épidémiologiques à l'échelle de quelques kilomètres, selon les pratiques d'élevage, l'utilisation de l'espace par les animaux et les hommes et donc l'intensité des contacts avec les vecteurs (Laveissière et al., 1986).

- Des glossines plus ou moins dangereuses

Les résultats des dissections de glossines ont montré que deux parties du réseau hydrographique se distinguent plus particulièrement par leur taux élevé d'infection, une à l'ouest (zone de Nyarafo-Ménégué), l'autre à l'est (zone de Yéguéré-Ouara) (fig. 10). Cependant les organes infectés sont différents entre ces deux zones. Les analyses par PCR ont confirmé que dans ces deux zones, les vecteurs n'hébergent pas les mêmes parasites et ne se nourrissent pas sur les mêmes hôtes (tableaux II, III et fig. 11). Les glossines riveraines ont en effet des préférences trophiques peu marquées, et s'alimentent sur les hôtes les plus disponibles (Chal-

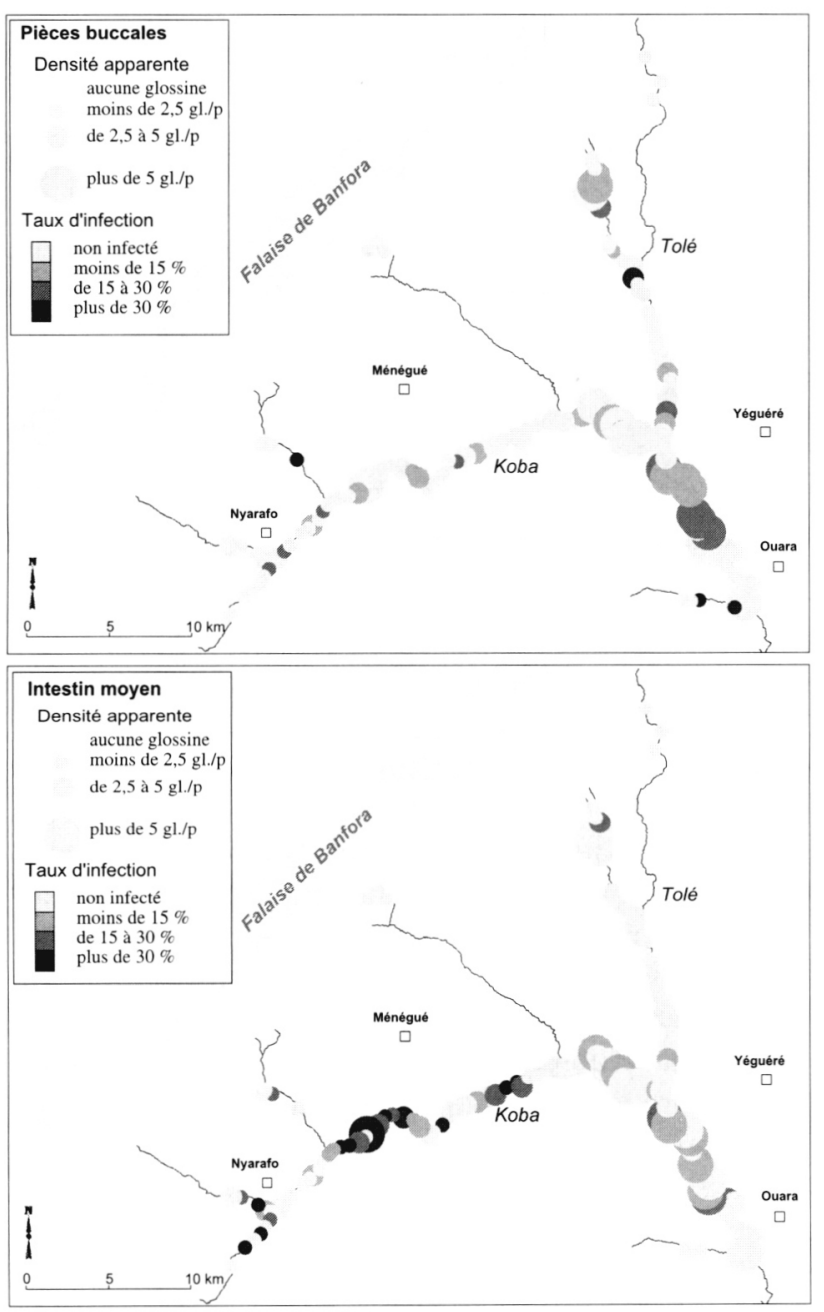

Fig. 10. - Densités apparentes (nombre de glossines/piège/jour) et taux d'infection des pièces buccales et de l'intestin moyen chez Glossina tachinoides (chaque symbole représente une moyenne de capture sur cinq pièges)

\begin{tabular}{lcc}
\hline & Nyarafo-Ménégué & Yéguéré-Ouara \\
\hline Insectes capturés & 426 & 1150 \\
Insectes disséqués & 330 & 524 \\
\hline Infection du tube digestif & $65,5^{1}$ & $20^{2}$ \\
Infection des pièces buccales & $22,7^{1}$ & $64,2^{2}$ \\
Repas sur des ruminants & $21,2^{3}$ & $42,8^{4}$ \\
Repas sur des suidés & $29,7^{3}$ & $26,5^{4}$ \\
Repas sur des reptiles & $36,4^{3}$ & $16,9^{4}$ \\
\hline Taux d'identification & 33,5 & 84,5 \\
\hline
\end{tabular}

$1: \mathrm{n}=84 ; 2: \mathrm{n}=77 ; 3: \mathrm{n}=30 ; 4: \mathrm{n}=116$

Tableau II. - Taux d'infection des différents organes et nature des repas sanguins selon la zone de capture de G. tachinoides.

\begin{tabular}{lccc}
\hline & $\begin{array}{c}\text { Nyarafo- } \\
\text { Ménégué }\end{array}$ & $\begin{array}{c}\text { Yéguéré- } \\
\text { Ouara }\end{array}$ & s \\
\hline T. vivax & $22,6^{1}$ & $58,4^{2}$ & ${ }^{* * *}$ \\
T. congolense type "savane" & $20,6^{1}$ & $32,5^{2}$ & ${ }^{* *}$ \\
T. congolense type "forêt" & $7,1^{1}$ & $10,4^{2}$ & $\circ$ \\
T. brucei s. $l$. & $3,6^{1}$ & $16,9^{2}$ & $*$ \\
\hline
\end{tabular}

$1: \mathrm{n}=84 ; 2: \mathrm{n}=77$.

Test du $\mathrm{Khi}^{2}$ significatif à : ${ }^{* * *}: 0,1 \% ;^{* *}: 1 \% ;^{*}: 5 \% ;^{\circ}$ : non significatif.

Tableau III. - Identification par PCR des trypanosomes selon la zone de capture, chez G. tachinoides (en pourcentage par rapport aux échantillons positifs à l'examen microscopique).

lier, 1973; Laveissière \& Boreham, 1976). Dans les zones faiblement occupées par l'homme (partie ouest, Nyarafo-Ménégué), les repas sanguins prélevés sur des reptiles (varans, crocodiles) sont majoritaires et les glossines ne portent que peu de trypanosomes pathogènes. En revanche, dans les zones fortement anthropisées (partie est, Yéguéré-Ouara), les vecteurs se nourrissent essentiellement sur les bovins et les suidés, et sont infectées par des parasites pathogènes (de La Rocque, 1997; Lefrançois et al., 1998). Ces résultats, ramenés à la population des glossines capturées et à la superficie de chacune des zones séparées d'une dizaine de kilomètres seulement font apparaître deux situations très différentes : la densité de glossines porteuses de trypanosomes reconnus pathogènes est de 2,6 individus par kilomètre de réseau hydrographique dans la zone ouest, et de 6,9 individus par kilomètre dans la zone est.

- Une approche globale pour évaluer le risque à l'échelle du parcours

Dans la littérature, le risque trypanosomien pour le cheptel est classiquement relié à l'importance quantitative des vecteurs (Lambrecht, 1980; Rogers, 1985; Milligan \& Baker, 1988; Leak et al., 1993; Claxton et al., 1992). Cette relation entre les densités de glossines et la pression de transmission est bien admise avec des 

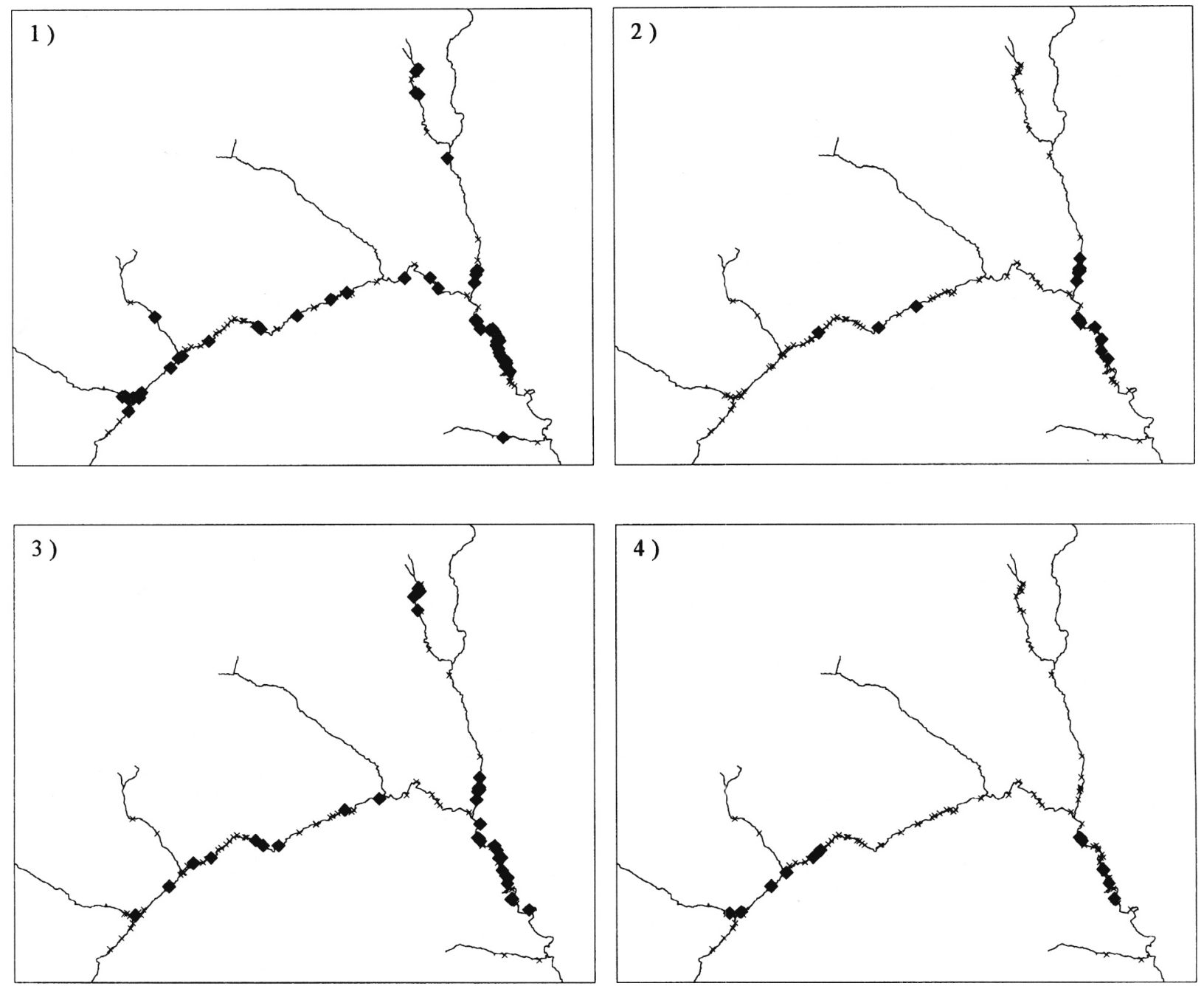

Fig. 11. - Localisation des organes infectés positifs aux réactions d'amplification par PCR.

mouches de savanes qui ont une distribution large, une bonne compétence vectorielle pour les trypanosomes du bétail et des capacités de dispersion saisonnière rapides et amples, amenant à considérer leur répartition spatiale comme homogène. Des études ont cependant montré que dans une savane colonisée par G. morsitans submorsitans, la pression glossinienne pouvait varier de 1 à 10 selon les troupeaux et leurs lieux de pâture (Wacher et al., 1994), et qu'à grande échelle, la transmission parasitaire était hétérogène dans l'espace (Rawlings et al., 1991).

Dans le cas des glossines ripicoles étroitement inféodées aux formations végétales riveraines, les zones de contact entre les vecteurs et les bovins sont encore plus circonscrites. Le risque n'est pas lié seulement aux densités de glossines, mais à l'intensité des interfaces spatiales et temporelles entre le bétail et les vecteurs. Une faible population de glossines fréquemment au contact des animaux domestiques (ou des hommes) au niveau des points d'abreuvement par exemple peut assurer une transmission intense et régulière (Frezil et al., 1980; D'Amico, 1993; Laveissière et al., 1986). Des systèmes épidémiologiques très différents se succèdent à quelques kilomètres de distance, selon l'articulation des milieux naturels (faune sauvage, végétation, cours d'eau) et humains (agriculture, parcours des animaux, pratiques d'élevage). L'évaluation du risque impose de replacer le fonctionnement du système de transmission dans l'environnement global de la zone étudiée, et d'avoir une approche multidisciplinaire et systémique des différents processus écologiques, biophysiques et sociaux qui façonnent des paysages épidémiologiques et donnent naissance aux systèmes "éco-socio-pathogènes" (Picheral, 1982; Amat-Roze \& Gentilini, 1995).

L'articulation entre les différentes informations provenant de sources différentes (images satellitales, photographies aériennes, enquêtes de terrain, travaux de laboratoire) et de disciplines variées se réalise autour de leur identifiant géographique, au sein du SIG 
a)

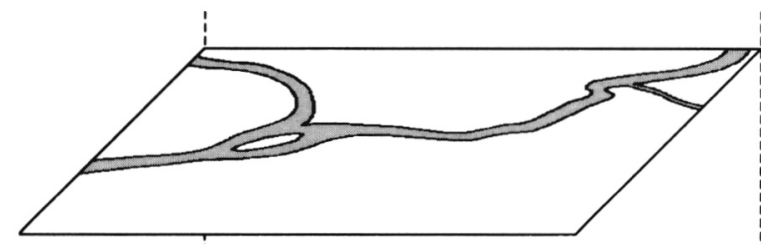

b)

c)

d)
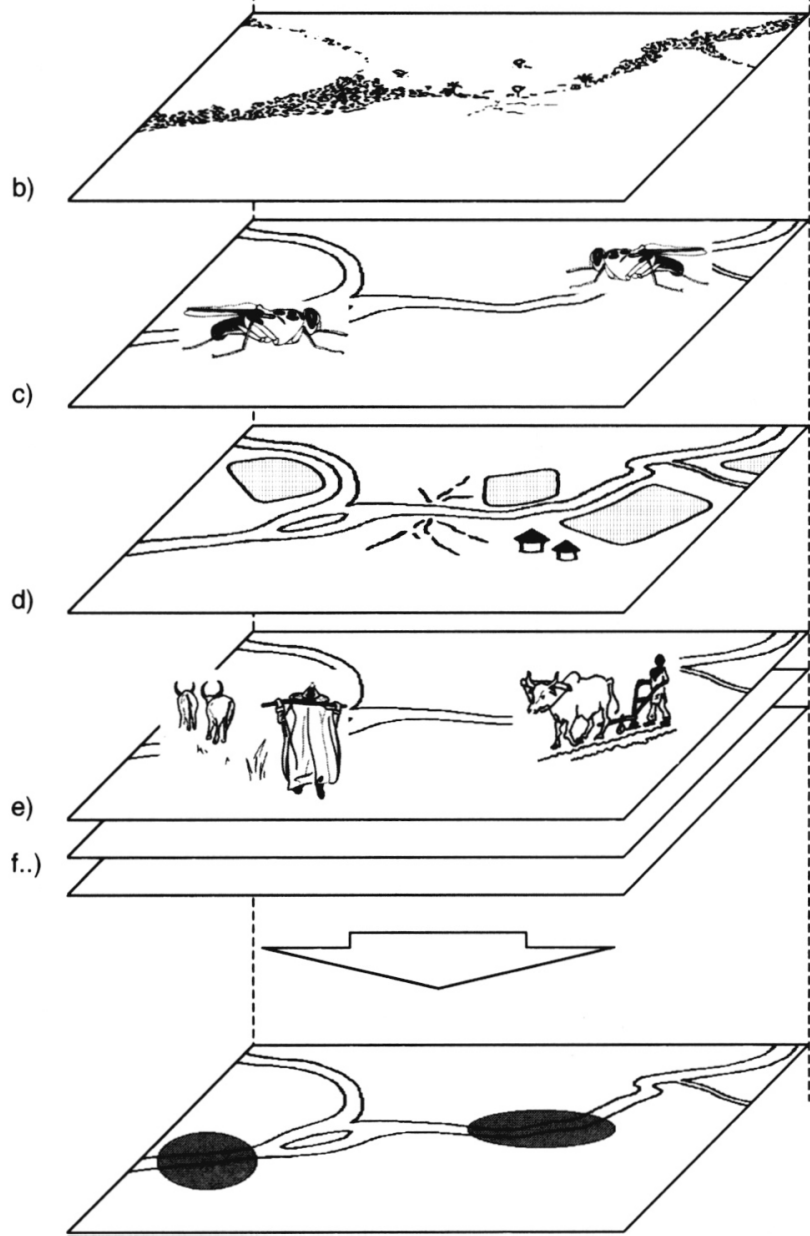

Fig. 12. - Superposition d'informations au sein du SIG pour révéler les sites de transmission

a) réseau hydrographique; b) végétation naturelle; c) distribution et abondance des glossines; d) occupation agricole; e) densité de bovins, systèmes d'élevage; f..) physiographie, densité humaine...

(fig. 12). Ceci sous-entend des procédures parfois complexes de traitement de données multi-sources, multiéchelles et multi-dates.

\section{LA RECHERCHE D'INDICATEURS}

\section{IDENTIFICATION DES PAYSAGES ENTOMOLOGIQUES}

$\mathrm{P}$ our chaque site de capture, des informations concernant la structure de la végétation, celle du cours d'eau et la fréquentation du site par les animaux et les hommes ont été relevées (environ
70 variables). Les différents paramètres écologiques ont été confrontés aux résultats entomologiques. Des corrélations entre les densités d'insectes et chacune des variables écologiques ont dans un premier temps été mises en évidence. Dans un second temps, des typologies ont été réalisées pour décrire de manière synthétique les différentes formations végétales, les architectures de cours d'eau et la fréquentation par les hôtes nourriciers des mouches. Ces typologies ont été obtenues par des analyses factorielles des correspondances suivies de regroupements par la méthode des nuées dynamiques (logiciel SAS ${ }^{\mathrm{TM}}$ ) (de La Rocque, 1997). Les informations de terrain, les résultats des typologies et les données de télédétection ont été importés dans un Système d'Information Géographique (logiciels IDRISI ${ }^{\mathrm{TM}}$ et MAPINFO $^{\mathrm{TM}}$ ).

\section{- Caractérisation des biotopes}

Les tableaux IV et V illustrent les correspondances entre l'abondance de chacune des espèces de glossines et les principales variables écologiques relevées. Pour G. tachinoides, les plus fortes corrélations ont été obtenues avec la largeur de la galerie, la hauteur des berges, l'ouverture de la voûte végétale et la présence de faune sauvage. Pour G. p. gambiensis, elles l'ont été avec la largeur et la hauteur de la galerie, l'encaissement des berges du cours d'eau, la densité de la lisière et la présence de faune sauvage. Les paramètres considérés n'étant pas indépendants, l'intérêt de cette analyse demeure relatif.

Cinq principales architectures de formations végétales ont été mises en évidence par les typologies et nommées selon une nomenclature personnelle. Elles sont décrites en figure 13, où ne sont indiquées que les modalités qui ont le plus contribué aux analyses factorielles. Les galeries forestières denses correspondent à des formations larges, avec un fort recouvrement et protégées des savanes avoisinantes. Les forêts-galeries sont des structures très larges, hautes, denses, avec un sous-bois encombré. Les cordons ripicoles denses sont étroits, avec des arbres de taille élevée, un recouvrement important mais une strate inférieure éclaircie. Les cordons ripicoles lâches sont étroits, et associent formations arborées et formations buissonnantes plus ou moins ouvertes. Les bosquets correspondent aux petites formations ligneuses présentes le long des lignes de drainage en zone de savane.

Sept types d'architectures de cours d'eau se distinguent (fig. 14). Les facteurs discriminants concernent la durée d'inondation, l'enclavement et la hauteur des berges et le recouvrement par la voûte végétale. Ces architectures décrivent ainsi des rivières plus ou moins ouvertes et inondées, des "ravins en U" dans les zones soumises à d'intenses ruissellements et des prairies dans les zones de savane. 


\begin{tabular}{|c|c|c|c|c|c|c|c|c|}
\hline & & \multirow[b]{2}{*}{$\mathbf{n}$} & \multicolumn{3}{|c|}{ G. tachinoides } & \multicolumn{3}{|c|}{ G. p. gambiensis } \\
\hline & & & aucune & de 1 à 6 & plus de 7 & aucune & de 16 & plus de 7 \\
\hline \multirow[t]{4}{*}{ Largeur totale } & inf. à 10 & 192 & 90,1 & 9,9 & 0,0 & 94,8 & 5,2 & 0,0 \\
\hline & de 10 à 25 & 300 & 51,0 & 43,0 & 6,0 & 59,0 & 35,7 & 5,3 \\
\hline & de 25 à 40 & 351 & 32,2 & 54,4 & 13,4 & 39,3 & 53,6 & 7,1 \\
\hline & plus de 40 & 119 & 35,3 & 45,4 & 19,3 & 47,1 & 47,0 & 5,9 \\
\hline \multirow[t]{4}{*}{ Hauteur moyenne } & inf. à 8 & 247 & 66,0 & 27,1 & 6,9 & 72,1 & 23,0 & 4,9 \\
\hline & de 8 à 10 & 236 & 44,1 & 43,2 & 12,7 & 55,5 & 35,2 & 9,3 \\
\hline & de 10 à 15 & 305 & 43,9 & 45,9 & 10,2 & 46,6 & 50,1 & 3,3 \\
\hline & plus de 15 & 174 & 46,0 & 48,3 & 5,7 & 58,6 & 39,1 & 2,3 \\
\hline \multirow[t]{4}{*}{ Recouvrement } & inf. à $25 \%$ & 247 & 76,1 & 19,5 & 4,4 & 83,0 & 15,8 & 1,2 \\
\hline & de 25 à $50 \%$ & 217 & 42,9 & 44,7 & 12,4 & 57,6 & 38,2 & 4,2 \\
\hline & de 50 à $75 \%$ & 337 & 40,1 & 50,5 & 10,4 & 50,4 & 43,1 & 6,5 \\
\hline & plus de $75 \%$ & 161 & 40,4 & 50,3 & 9,3 & 32,9 & 58,4 & 8,7 \\
\hline \multirow[t]{3}{*}{ Densité de la lisière } & inf. à 1 & 394 & 68,0 & 26,4 & 5,6 & 73,9 & 15,1 & 11,0 \\
\hline & de 1 à 2 & 431 & 37,3 & 50,1 & 12,6 & 49,9 & 44,3 & 5,8 \\
\hline & plus de 2 & 137 & 38,0 & 53,2 & 8,8 & 34,3 & 54,8 & 10,9 \\
\hline
\end{tabular}

Les densités apparentes ont été réparties en trois classes d'abondances, assurant un équilibre des effectifs : aucune glossine capturée par piège, de une à six glossine(s) capturée(s) par piège, plus de sept glossines capturées par piège. Les largeurs et hauteurs sont en mètres. La densité de la lisière est estimée selon un code allant de 1 (lisière perméable) à 4 (lisière imperméable).

Tableau IV. - Fréquence des captures selon les principaux descriptifs de la formation végétale.

\begin{tabular}{|c|c|c|c|c|c|c|c|c|}
\hline & & \multirow[b]{2}{*}{$\mathbf{n}$} & \multicolumn{3}{|c|}{ G. tachinoides } & \multicolumn{3}{|c|}{ G. p. gambiensis } \\
\hline & & & aucune & de 1 à 6 & plus de 7 & aucune & de 16 & plus de 7 \\
\hline \multirow[t]{4}{*}{ Régime } & inf. à 6 mois & 158 & 89,8 & 8,9 & 1,3 & 89,9 & 8,8 & 1,3 \\
\hline & de 6 à 8 mois & 497 & 49,5 & 40,6 & 9,9 & 61,2 & 35,0 & 3,8 \\
\hline & de 8 à 11 mois & 220 & 29,5 & 60,1 & 10,4 & 34,5 & 60,5 & 5,0 \\
\hline & permanent & 87 & 32,2 & 51,7 & 16,1 & 35,6 & 46,0 & 18,4 \\
\hline \multirow[t]{4}{*}{ Forme des berges } & très encaissées & 328 & 43,6 & 47,6 & 8,8 & 49,1 & 46,6 & 4,3 \\
\hline & très encaissées & 260 & 39,6 & 50,8 & 9,6 & 49,2 & 42,7 & 8,1 \\
\hline & inclinées & 218 & 46,3 & 40,4 & 13,3 & 54,6 & 40,4 & 5,0 \\
\hline & horizontales & 156 & 85,9 & 10,9 & 3,2 & 92,9 & 5,8 & 1,3 \\
\hline \multirow[t]{4}{*}{ Hauteur des berges } & inf. à 0,5 mètre & 243 & 78,6 & 16,1 & 5,3 & 79,8 & 18,6 & 1,6 \\
\hline & de 0,5 à 1 mètre & 255 & 40,4 & 48,6 & 11,0 & 53,3 & 41,2 & 5,5 \\
\hline & de 1 à 2 mètres & 310 & 41,9 & 48,1 & 10,0 & 48,7 & 44,5 & 6,8 \\
\hline & sup. à 2 mètres & 154 & 37 & 52,6 & 10,4 & 46,7 & 47,5 & 5,8 \\
\hline \multirow[t]{4}{*}{ Type de voûte } & fermée & 286 & 40,6 & 51,4 & 8,0 & 38,1 & 54,9 & 7,0 \\
\hline & 1/4 ouverte & 138 & 31,2 & 55,8 & 13,0 & 42,7 & 50,1 & 7,3 \\
\hline & 1/2 ouverte & 172 & 39,5 & 46,5 & 14,0 & 53,5 & 40,1 & 6,4 \\
\hline & plus de $3 / 4$ ouverte & 366 & 69,4 & 24,3 & 6,3 & 80,0 & 18,1 & 1,9 \\
\hline
\end{tabular}

Les densités apparentes ont été réparties en trois classes d'abondances assurant un équilibre des effectifs : aucune glossine capturée par piège, de une à six glossine(s) capturée(s) par piège, plus de sept glossines capturées par piège. Les largeurs et hauteurs sont en mètres.

Tableau V. - Fréquence des captures selon les principaux descriptifs du cours d'eau.

Ces différentes classes de typologies, aisément identifiables sur le terrain, permettent de résumer la variabilité des structures écologiques rencontrées dans la zone. Elles correspondent assez fidèlement aux descriptions des biotopes de ces deux espèces décrites dans la littérature (Challier, 1973; Gruvel, 1974).

Les densités apparentes moyennes de glossines (ou nombre d'individus capturés par piège et par jour) ont été mises en relation avec les architectures végétales (fig. 13) et les architectures de cours d'eau (fig. 14). Les deux espèces de glossines sont abondantes dans les forêts-galeries et les galeries forestières. Les cordons sont peu favorables à G. p. gambiensis et les bosquets sont défavorables aux deux espèces. Les "rivières de galeries fermées" sont les architectures dans lesquelles les captures des deux espèces ont été les plus abondantes. G. tachinoides se rencontre également dans les cours d'eau temporaires et ouverts, à l'exception toutefois des prairies hydromorphes. 


\begin{tabular}{|c|c|c|c|c|c|}
\hline & 1 & 2 & 3 & 4 & 5 \\
\hline Nombre de pièges & 139 & 178 & 147 & 188 & 191 \\
\hline Largeur & sup. $25(0,76)$ & $25-40(0,61)$ & $10-25(0,55)$ & $10-25(0,52)$ & inf. $10(0,84)$ \\
\hline Hauteur moyenne & sup. 15 (1) & $8-10(0,51)$ & sup. $15(0,54)$ & $8-10(0,40)$ & inf. $8(0,69)$ \\
\hline Hauteur maximale & $18-25(0,52)$ & $15-18(0,39)$ & $18-25(0,53)$ & $15-18(0,34)$ & inf. $14(0,64)$ \\
\hline Hauteur minimale & sup. $9(0,92)$ & $6-9(0,65)$ & sup. $9(0,87)$ & $6-9(0,55)$ & inf. $6(0,84)$ \\
\hline Recouvrement & sup. $75(0,48)$ & $50-75(0,56)$ & $50-75(0,42)$ & $25-50(0,47)$ & inf. $25(0,83)$ \\
\hline Herbacées & $0(0,64)$ & $0(0,56)$ & $0(0,46)$ & $1(0,40)$ & sup. $1(0,55)$ \\
\hline Buissons & sup. $1(0,75)$ & $1.5(0,81)$ & sup. $1(0,58)$ & sup. $1(0,41)$ & inf. $0.5(0,60)$ \\
\hline Racines & sup. $1.5(0,88)$ & $1.5(0,85)$ & $0.5-1.5(0,57)$ & $0.5-1.5(0,53)$ & inf. $0.5(0,89)$ \\
\hline Densité de la lisière & $1-2(0,55)$ & $1-2(0,62)$ & $1-2(0,59)$ & $1-2(0,52)$ & inf. $1(0,84)$ \\
\hline G. tachinoides & 2,7 & 2,9 & 1,4 & 2,6 & 0,2 \\
\hline G. p. gambiensis & 1,9 & 2,8 & 0,9 & 1,5 & 0,1 \\
\hline
\end{tabular}

1 : forêt-galerie -2 : galerie forestière -3 : cordon dense -4 : cordon lâche -5 : bosquet.

Fig. 13. - Architectures de formations végétales, principales modalités et densités de glossines correspondantes. Entre parenthèse sont indiqués les fréquences des modalités. Les largeurs et hauteurs sont en mètres. Le recouvrement est en pourcentage. Les grilles des indices sont les suivantes : importance des herbacées, des buissons et des racines : de 0 (absent) à 4 (très abondant); densité de la lisière : de 1 (perméable) à 4 (imperméable). Les densités apparentes correspondent au nombre de glossines capturées par piège et par jour.

\begin{tabular}{|c|c|c|c|c|c|c|c|c|}
\hline & 1 & 2 & 3 & 4 & 5 & 6 & 7 & 8 \\
\hline Nombre de pièges & 63 & 78 & 159 & 191 & 191 & 136 & 139 & 47 \\
\hline Durée d'inondation & $12(1)$ & $8-11(0,5)$ & $8-11(0,6)$ & $6-8(0,4)$ & $6-8(0,8)$ & $6-8(0,7)$ & $<6(0,6)$ & $<6(0,5)$ \\
\hline Encaissement & $2(1)$ & $2(0,8)$ & $1(0,9)$ & $1(1)$ & $3(0,9)$ & $2(0,9)$ & $4(0,9)$ & $1(1)$ \\
\hline Hauteur des berges & $1-2(1)$ & $1-2(1)$ & $1-2(0,8)$ & $>2(0,9)$ & $0,5-1(0,6)$ & $0,5-1(0,6)$ & $<0,5(1)$ & $<6(0,9)$ \\
\hline Recouvrement & $4(0,5)$ & $1(0,5)$ & $1(1)$ & 1 ou 4 & $1,2,3,4$ & $4(0,4)$ & $4(0,9)$ & $4(0,5)$ \\
\hline DAP G. tachinoides & 1,5 & 3,1 & 2,6 & 2,3 & 2,7 & 2,1 & 0,3 & 1,1 \\
\hline DAP G.p. gambiensis & 1,9 & 2,8 & 1,9 & 1,4 & 1,4 & 1 & 0,1 & 0,4 \\
\hline
\end{tabular}

1 : rivière de galerie ouverte -2 : rivière de galerie fermée, peu encaissée -3 : rivière de galerie fermée, encaissée -4 : rivière temporaire, encaissée -5 : rivière temporaire, peu encaissée -6 : petite rivière -7 : prairie -8 : ravin en $U$.

Fig. 14. - Architectures de cours d'eau, principales modalités et densités apparentes correspondantes. Entre parenthèse sont indiqués les fréquences des modalités. Les durées d'inondations sont en mois. L'encaissement est noté de 1 (très encaissé) à 4 (horizontal). Le recouvrement par la voûte végétale est noté $(1)=$ galerie fermée, $(2)=1 / 4$ ouverte, $(3)=1 / 2$ ouverte, $(4)=3 / 4$ ou totalement ouverte. Les densités apparentes correspondent au nombre de glossines capturées par piège et par jour.

- Caractérisation des formations riveraines par télédétection

Par le passé, les photographies aériennes ont couramment été utilisées pour la cartographie des biotopes à glossines. Cependant les techniques de photo-interprétation sont lourdes et difficilement utilisables sur de grandes superficies. Les images satellitales sont mieux adaptées aux généralisations sur de vastes étendues et aux traitements semi-automatiques et reproductibles. Une scène SPOT couvrant la zone d'étude et datant de début novembre 1996 a été acquise. Cette date cor- respond au meilleur compromis entre la recherche de contraste entre les formations ligneuses et herbacées, et la perturbation du signal dans le visible et le proche infrarouge liée aux nuages de la saison des pluies ou à la poussière de l'harmattan. Lors d'enquêtes sur le terrain réalisées sur 164 sites jugés représentatifs de la diversité observée sur l'image, 13 types de milieu (ou unités cartographiques), orientés sur les formations de basfonds (6 unités), ont été déterminés. Les sites correspondants ont servi de références (ou "zones d'apprentissage") pour classer l'ensemble de l'image. La 


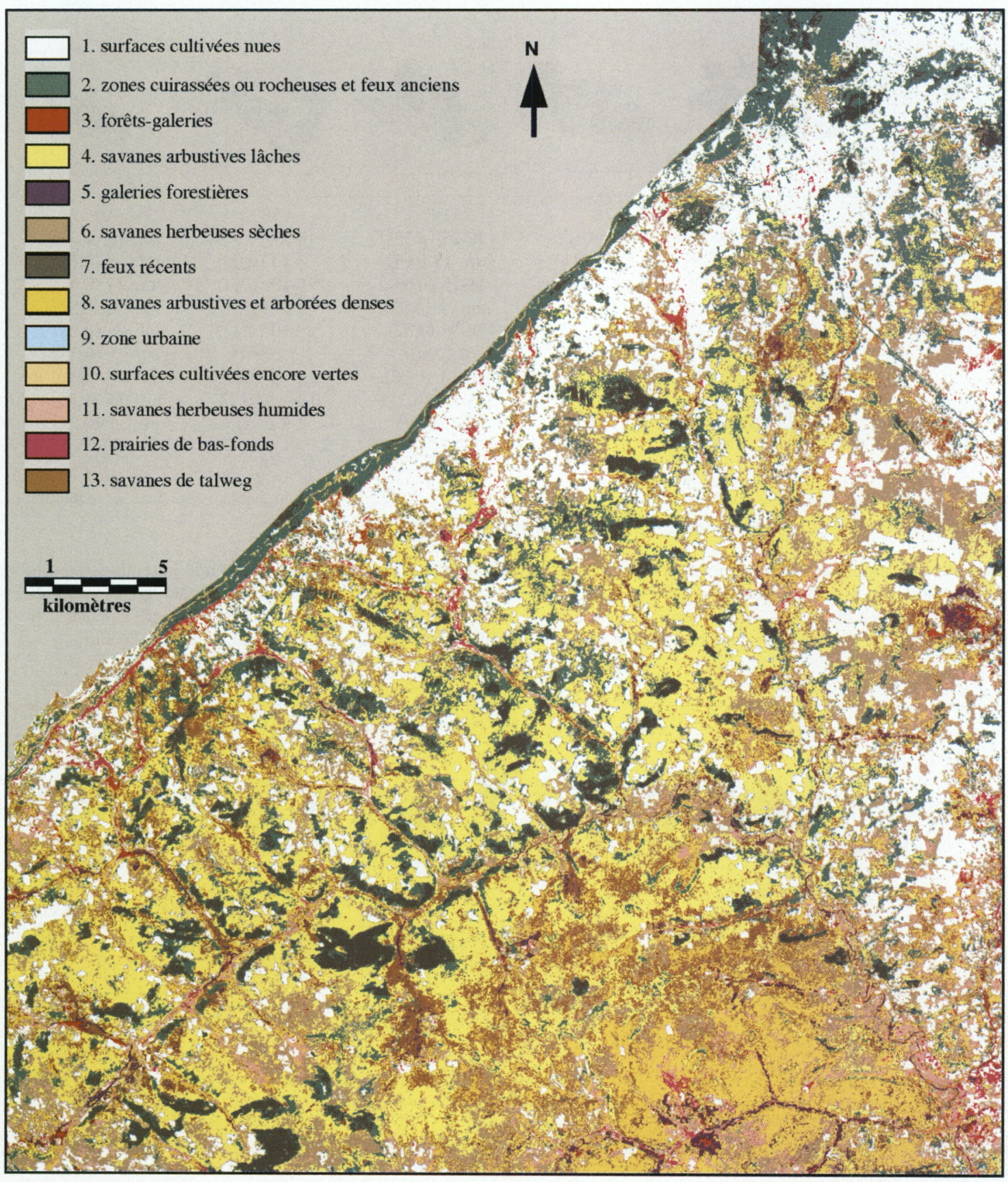

Coefficients Kappa

Thème $1: 0.9431$

Thème $2: 0.8923$

Thème $3: 0.5425$

Thème $4: 0.3462$

Thème $5: 0.6519$

Thème $6: 0.2903$
Thème $7: 0.9242$

Thème $8: 0.9186$

Thème $9: 0.7360$

Thème $10: 0.7394$

Thème $11: 0.3292$

Thème $12: 0.5716$

Thème $13: 0.1178$

Avec un Kappa égal à 1, la classification est "parfaite"; elle équivaut à un arrangement au hasard. Une classification est jugée excellente à partir de 0.75 .

Kappa global : 0.7074

Fig. 15. - Classification supervisée de l'image SPOT XS du 3 novembre 1996. 
classification dirigée repose sur l'utilisation d'un algorithme dit du "maximum de vraisemblance", qui sur la base des caractéristiques spectrales de chaque pixel de l'image l'affecte dans l'unité statistiquement la plus proche.

Le résultat de la classification est présenté en figure 15 . Une première analyse visuelle permet de repérer les structures linéaires du réseau hydrographique, ainsi que les espaces densément cultivés à l'est du Tolé et au pied de la falaise. Au sud de la Koba, les savanes arborées apparaissent dominantes.

L'évaluation quantitative de la classification est obtenue par l'analyse de la "matrice d'erreur" qui se réfère à des parcelles décrites sur le terrain et non utilisées lors du traitement. L'analyse des coefficients Kappa thème par thème révèle des objets mieux classés que d'autres ; ainsi, les surfaces cultivées, les affleurements rocheux, les zones brûlées et les savanes arborées denses sont bien repérées. En revanche, les thèmes relatifs à la végétation riveraine sont difficilement discriminés (fig. 15). Avec un coefficient Kappa global de 0.7074, le résultat de cette classification peut cependant être validé.

\section{- L'approche paysagère}

Les ambiguïtés de discrimination des formations ligneuses riveraines sont liées à leur taille, souvent de l'ordre de celle des pixels de l'image (20 mètres en mode multispectral), et aux confusions radiométriques avec les formations végétales périphériques de recouvrement et de phénologie voisines (prairies de basfond, savanes denses). Pour supprimer ces ambiguités et permettre une analyse indépendante de l'échelle, l'étape suivante a considéré les unités cartographiques non pas comme des entités propres, mais comme des éléments de paysages d'un niveau supérieur qui intègrent les différentes unités élémentaires existant en périphérie du réseau hydrographique. Les formations végétales ne sont en effet pas indépendantes des caractéristiques hydrologiques, géomorphologiques ou même anthropiques des bassins versant, et des résultats publiés par ailleurs ont montré que les densités des glossines riveraines pouvaient être reliées aux paysages de vallées (de La Rocque et al., 2001a). La définition d'une typologie paysagère des bas-fonds a permis alors de réduire l'échelle de perception.

Un paysage peut être défini comme "le résultat de la combinaison dynamique (...) d'éléments physiques, biologiques et anthropiques qui, en réagissant les uns sur les autres (en font) un ensemble unique et indissociable". (G. Bertrand, 1968 : In : Rougerie \& Beroutchachvili, 1991). En télédétection, il correspond à une combinaison d'états de surface et traduit l'agencement spatial des couleurs et les relations qu'elles ont entre elles (Kaiser, 1995). L'analyse spatiale mise en ouvre dans le logiciel PAPRI (PAysages définis a PRIori, Cirad) prend en compte la distribution des thèmes à l'intérieur d'une fenêtre mobile. La classification repose sur le calcul du pourcentage de chaque thème à chaque instant dans la fenêtre, en comparaison à des paysages de référence (Borne, 1989).

En s'appuyant sur la connaissance du terrain, huit unités de paysage ont été retenues. La correspondance entre les différentes unités de paysage et les éléments définis lors des typologies apparait dans le tableau VI. La classification a été réalisée dans une zone tampon de 600 mètres de large, centrée sur réseau hydrographique. L'ensemble du réseau hydrographique a ainsi pu être segmenté selon les différentes classes de paysages (fig. 16).

\section{- Les paysages favorables aux glossines}

Les moyennes et écarts-type des densités apparentes de chaque espèce de glossines dans les paysages sont indiqués dans le tableau VII. Les densités des deux espèces sont significativement plus élevées dans

\begin{tabular}{|c|c|c|c|c|c|c|c|c|c|}
\hline & & \multicolumn{8}{|c|}{ Unité de paysage } \\
\hline & & $\mathbf{1}$ & 2 & 3 & 4 & 5 & 6 & 7 & 8 \\
\hline \multirow{5}{*}{$\begin{array}{l}\text { Architecture } \\
\text { végétale }\end{array}$} & forêt-galerie & 20 & 24 & 16 & 7 & 4 & 0 & 15 & 58 \\
\hline & galerie forestière & 39 & 21 & 17 & 7 & 7 & 0 & 20 & 14 \\
\hline & cordon dense & 14 & 21 & 19 & 28 & 4 & 5 & 0 & 14 \\
\hline & cordon lâche & 24 & 28 & 22 & 24 & 8 & 6 & 30 & 0 \\
\hline & bosquet & 3 & 6 & 26 & 34 & 77 & 89 & 35 & 14 \\
\hline \multirow{7}{*}{$\begin{array}{l}\text { Architecture } \\
\text { de cours } \\
\text { d'eau }\end{array}$} & rivière peu encaissée de galerie fermée & 17 & 10 & 9 & 2 & 0 & 0 & 31 & 0 \\
\hline & rivière encaissée de galerie fermée & 8 & 12 & 9 & 5 & 0 & 0 & 0 & 0 \\
\hline & rivière temporaire encaissée & 30 & 14 & 16 & 4 & 29 & 6 & 12 & 0 \\
\hline & rivière temporaire peu encaissée & 25 & 31 & 24 & 41 & 0 & 0 & 13 & 16 \\
\hline & petite rivière & 11 & 24 & 21 & 15 & 17 & 0 & 7 & 17 \\
\hline & prairie hydromorphe & 6 & 6 & 14 & 33 & 46 & 82 & 25 & 67 \\
\hline & ravin en $\mathrm{U}$ & 3 & 4 & 7 & 0 & 8 & 12 & 12 & 0 \\
\hline
\end{tabular}

Pour chaque paysage est indiquée la fréquence de chaque modalité.

Tableau VI. - Correspondances entre les unités de paysages et les architectures de formations végétales et de cours d'eau. 


\begin{tabular}{llcccccccc}
\hline & Unité de paysage & $\mathbf{1}$ & $\mathbf{2}$ & $\mathbf{3}$ & $\mathbf{4}$ & $\mathbf{5}$ & $\mathbf{6}$ & $\mathbf{7}$ & $\mathbf{8}$ \\
\hline \multirow{2}{*}{ G. tachinoides } & nombre de sites & 242 & 194 & 343 & 57 & 30 & 38 & 23 & 11 \\
& moyenne & 3,85 & 1,89 & 1,94 & 0,8 & 1,17 & 0 & 1,61 & 2,27 \\
& écart-type & 5,96 & 2,76 & 3,55 & 2,9 & 0,46 & 0 & 1,95 & 3,9 \\
\hline \multirow{2}{*}{ G.p.gambiensis } & moyenne & 2,61 & 1,76 & 0,85 & 0,88 & 0,07 & 0 & 1,2 & 9,09 \\
& écart-type & 3,35 & 2,37 & 1,73 & 3,01 & 0,37 & 0 & 2,6 & 10,87 \\
\hline
\end{tabular}

Tableau VII. - Moyennes et écart-types des densités de glossines dans les différents paysages.

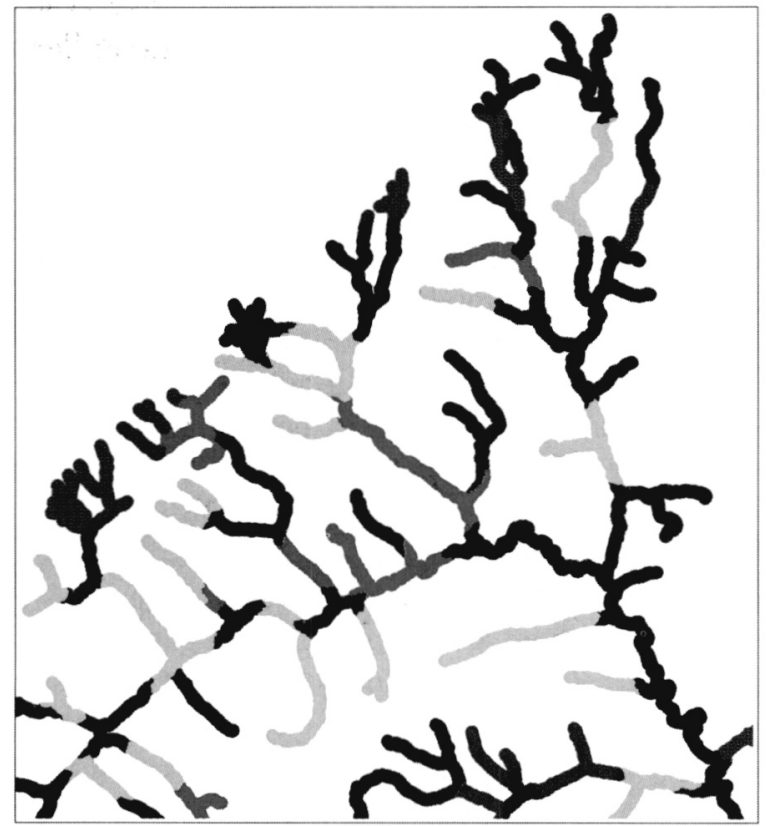

Unité 1 : paysage de galeries larges bordées de savanes herbeuses

Unité 2 : paysage de galeries étroites bordées de savanes arbustives ou arborées lâches

Unité 3 : paysage de cordons ripicoles étroits bordées de cultures ou de savanes lâches

Unité 4 : paysage de thalweg

Unite 5 : paysage de zones intensément cultivées

Unité 6 : paysage de savanes parcs

Unité 7 : paysage de gzones non classées (feux, cuirasse...)

Unité 8 : paysage de forêt

Fig. 16. - Distribution des différents paysages le long du réseau hydrographique.

l'unité 1 que dans toutes les autres $(\mathrm{p}<0,01)$. Celles de G. p. gambiensis le sont également dans l'unité 2 $(\mathrm{p}<0,05)$, et celles de $G$. tachinoides dans les unités 2 et $3(\mathrm{p}<0,01)$. Les moyennes sont élevées dans l'unité 8 , mais le faible nombre de pièges posés dans ce type de paysage ne permet pas d'effectuer de comparaisons statistiques robustes.

\section{RÉPARTITION DU CHEPTEL}

\section{- Recensement}

Un recensement exhaustif du cheptel bovin de la zone a été effectué d'avril à août 1997. Lors de cette opé- ration, les concessions de tous les propriétaires de bovins ont été positionnées à l'aide de récepteurs GPS, ainsi que tous les points d'eau fréquentés par ces animaux. Au cours des cinq mois d'enquête, 801 concessions ont été recensées, représentant environ 16500 bovins. Trois principaux types de systèmes de production ont été mis en évidence par des typologies (Michel et al., 1999). Le premier type correspond aux éleveurs Peuhl, gros propriétaires d'animaux (plus de 100 têtes en moyenne), et peut se diviser en éleveurs sédentarisés installés depuis plus de 25 ans et en éleveurs nouvellement arrivés, transhumant hors de la zone en saison sèche. Le deuxième type regroupe des agriculteurs allochtones arrivés depuis peu, propriétaires de quelques boufs de trait, et pour les plus anciens d'un petit troupeau de reproducteurs. Le dernier type, numériquement majoritaire, correspond aux agriculteurs d'ethnies locales, dont les troupeaux ne dépassent généralement pas cinq bovins, dont une ou deux paires de boufs de trait.

\section{- Modélisation des espaces pastoraux}

Ainsi que vu précédemment, les parcours quotidiens des troupeaux varient selon les saisons, les modes d'élevage, la zone agro-écologique et leur effectif. En saison sèche, ils sont essentiellement dictés par la recherche de points d'eau. Une modélisation prenant en compte ces différentes paramètres a permis d'affecter des espaces pastoraux à chacun des campements (Michel et al., 1999). Le modèle crée, autour de l'axe entre la concession et le point d'eau, une zone de présence probable du troupeau ou "zone d'usage", représentée par un polygone dont la surface dépend de la taille du troupeau et de la distance entre ces deux points (fig. 17).

\section{- Espace pastoral et espace agricole}

La projection des zones d'usage des bovins sur un maillage géographique et la sommation des effectifs associés a permis d'établir une carte de densité de fréquentation de l'espace par les bovins (fig. 18). La comparaison des cartes de répartition des bovins et de l'emprise agricole montre une liaison entre les systèmes d'élevage, le type de répartition des bovins et le zonage agro-écologique (fig. 19 et 20). Dans la partie 


\begin{tabular}{l|cc|cc}
\hline $\begin{array}{l}\text { Distance } \\
\text { parc-point d'eau }\end{array}$ & \multicolumn{2}{|c|}{ Moins de $4 \mathrm{~km}$} & \multicolumn{2}{c}{ Plus de $4 \mathrm{~km}$} \\
\hline Nombre de bovins & $<20$ & $>20$ & $<40$ & $>40$ \\
\hline Largeur du polygone & $1 \mathrm{~km}$ & $2 \mathrm{~km}$ & $500 \mathrm{~m}$ & $1 \mathrm{~km}$ \\
\hline
\end{tabular}

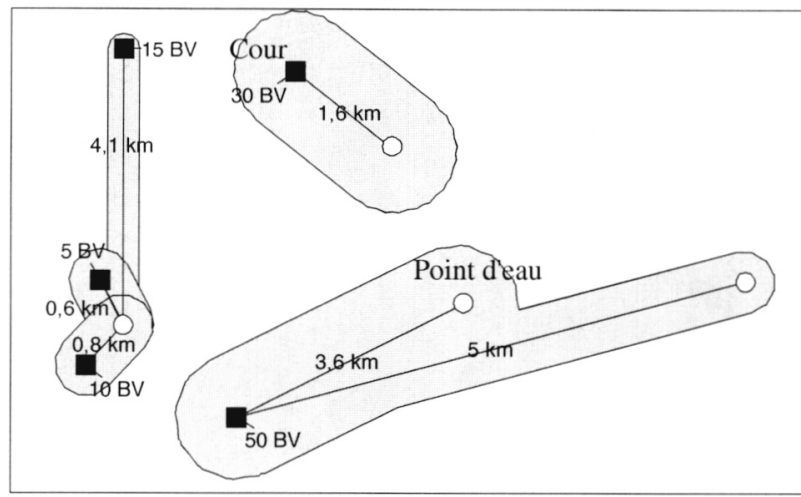

Fig. 17. - Polygones de zone d'influence des bovins entre la concession et le point d'abreuvement de fin de saison sèche (Michel et al., 1999).
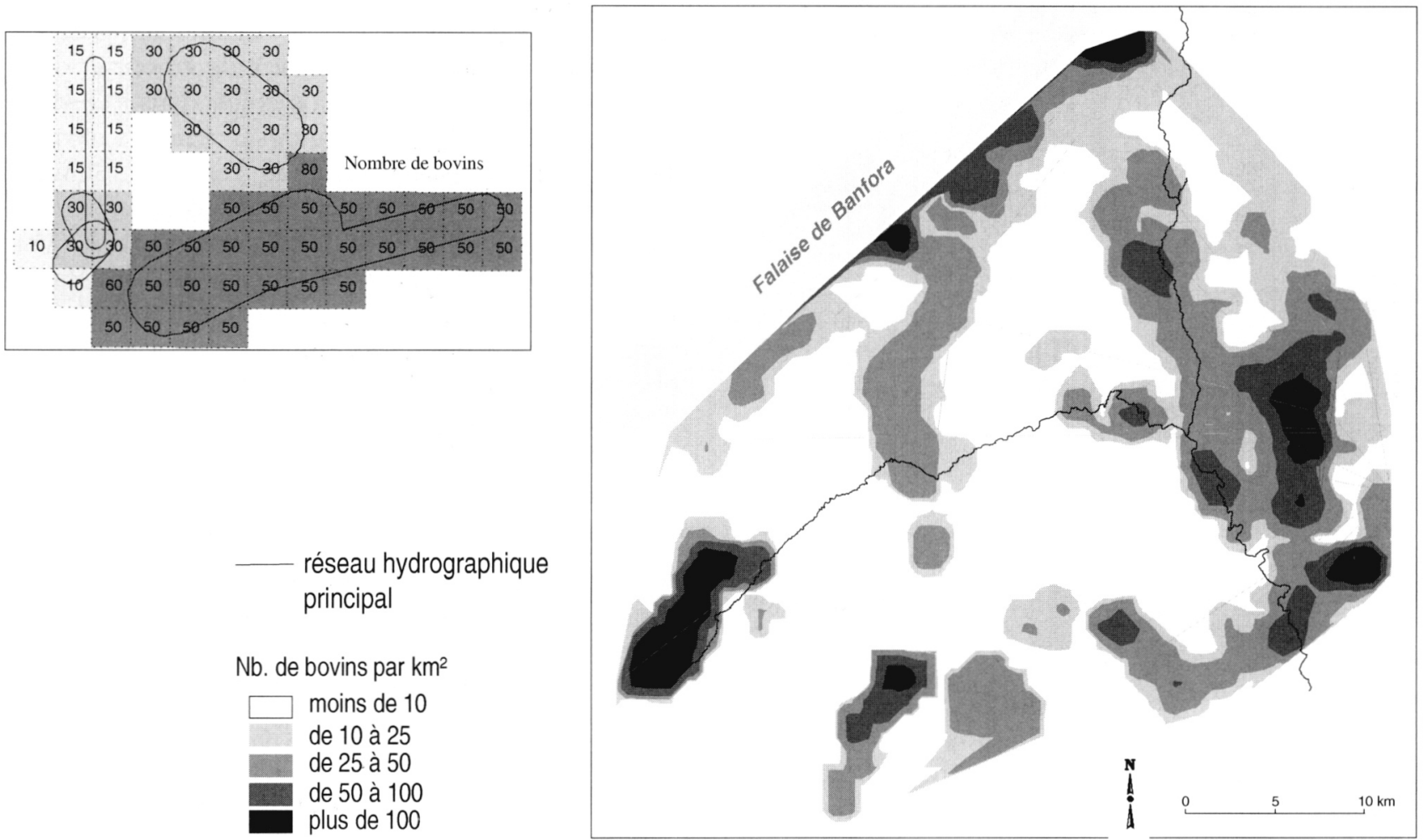

Fig. 18. - Répartition des bovins dans la zone de Sidéradougou. Carte obtenue par projection des polygones sur un maillage géographique puis lissage par régression locale. 


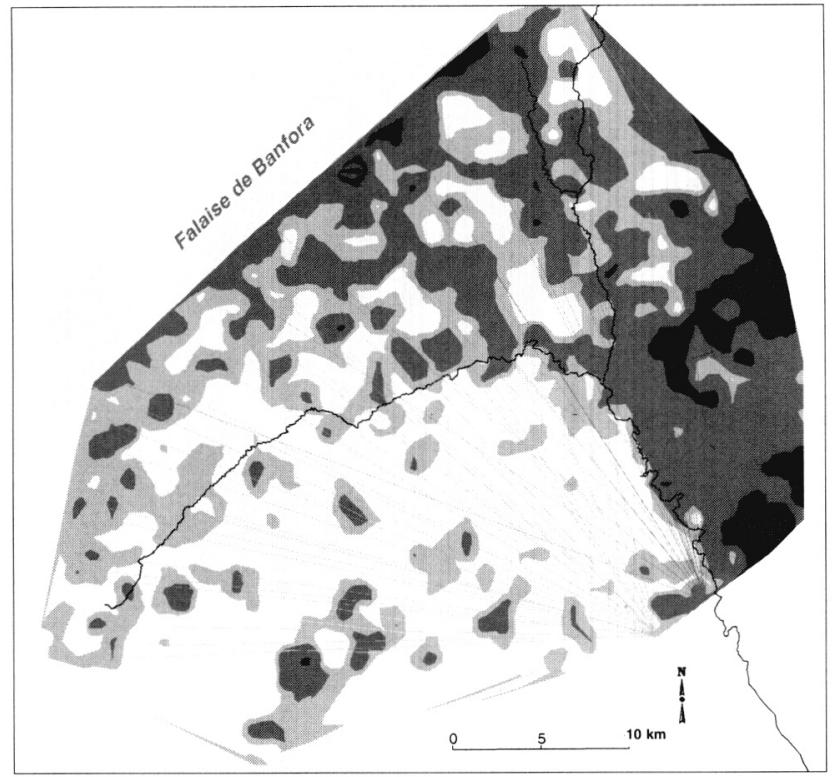

Densité de cultures moins de $10 \%$ de 10 à $25 \%$ de 25 à $50 \%$
plus de $50 \%$

Fig. 19. - Densités de cultures dans la zone de Sidéradougou. Carte obtenue par projection des parcelles agricoles sur un maillage géographique puis lissage par régression locale.

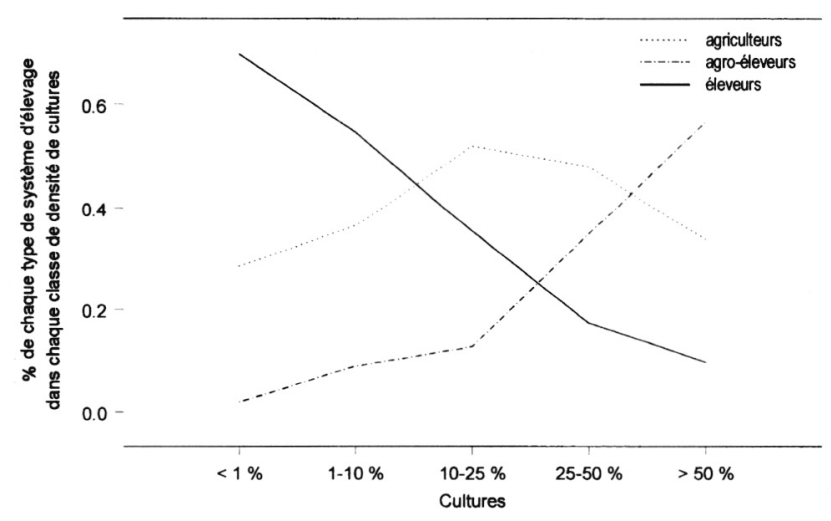

Fig. 20. - Correspondance entre l'occupation agricole et les types de systèmes d'élevages.

agricole, les agro-éleveurs qui possèdent des troupeaux de taille moyenne sont nombreux; l'accumulation de ces troupeaux entraîne des densités de bovins élevées et régulièrement réparties. Dans la partie agropastorale, des zones à faibles densités de bovins alternent avec des zones à fortes densités, correspondant à l'imbrication de petits éleveurs autochtones et de gros éleveurs Peuhl. Dans la partie pastorale, la densité de bovins est extrêmement variable; elle est très élevée aux alentours des campements Peuhl et très faible ou nulle dans le reste de l'espace.

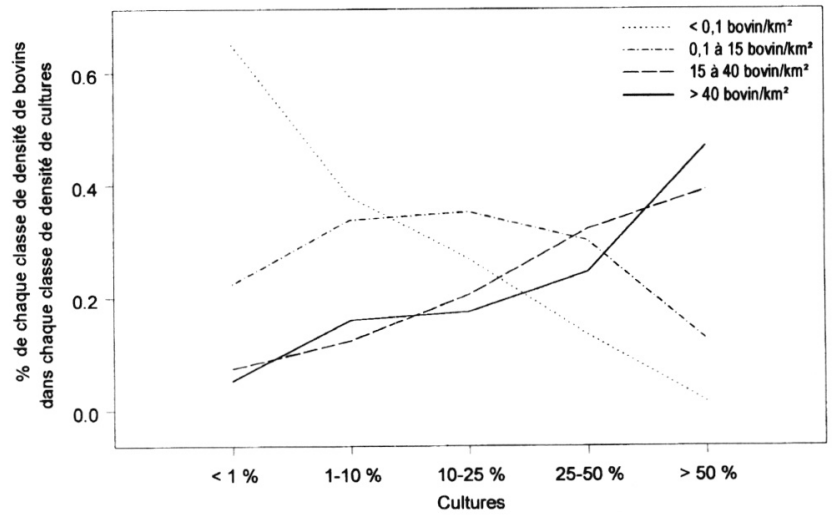

Fig. 21. - Correspondance entre les densités de bovins et l'occupation agricole?

A l'échelle de toute la zone, il n'existe pas de relation numérique continue entre les densités agricoles et animales. Ceci est dû à la forte variabilité de la densité de bovins dans les zones faiblement cultivées. Cependant, l'analyse de la répartition des différentes classes de densités de bovins dans les classes de densités de culture (Fig. 21) montre une liaison significative $(\mathrm{p}<$ 0,01). Dans la zone agricole, la densité de bovins est significativement plus élevée que dans les autres zones, reflétant l'importance des animaux de labour et de la thésaurisation des revenus agricoles dans l'élevage. Ceci confirme que les fortes emprises agricoles n'empêchent pas le développement de l'élevage (Slingenbergh \& Wint, 1997), contrairement aux idées reçues. L'occupation agricole peut permettre ainsi de prévoir la densité de bovins, sauf lorsqu'elle est trop faible (moins de $10 \%$ d'espace cultivé). Cette relation entre emprise agricole et présence du cheptel avait déjà été mise en évidence à l'échelle nationale ou régionale (Wint \& Bourn, 1994).

\section{ZONES D'INTERFACES}

\section{- Modèle spatial}

L'hypothèse de base du modèle est que les points épidémiologiquement les plus dangereux (PED) se situent à l'intersection de l'espace des glossines (EG) et de l'espace fréquenté par les bovin (EB). En fin de saison sèche, le réseau hydrographique (RH) est l'élément spatial central de ce modèle.

\section{$\mathrm{PED}=\mathrm{RH} \cap \mathrm{EG} \cap \mathrm{EB}$}

Le réseau hydrographique a été numérisé par interprétation simultanée d'une image SPOT panchromatique et de photographies aériennes à 1/50000. L'espace des glossines est caractérisé par les paysages de bas-fond les plus favorables aux insectes (unités 1, 2 et 8). L'espace des bovins a été perçu à travers la modélisation des zones d'usage du cheptel. Une grille de risque a été établie pour rechercher les combinai- 


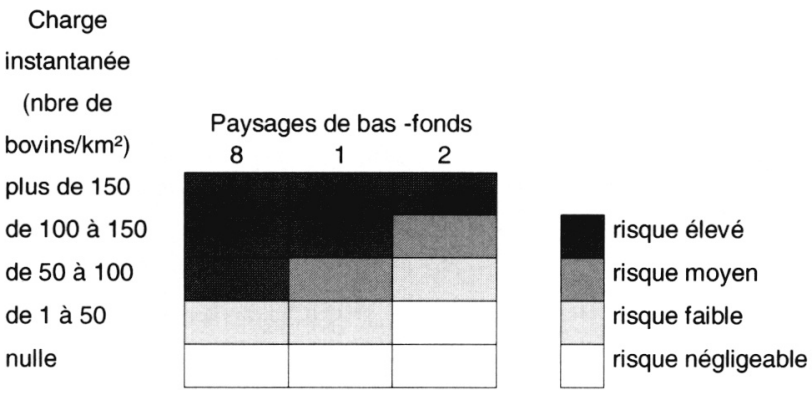

Fig. 22. - Grille de risque pour l'identification des zones à risque épidémiologique. sons les plus favorables à la transmission parasitaire (Fig. 22). La démarche révèle alors que sur les 126 km du réseau hydrographique concerné, $15 \mathrm{~km}$ appartiennent à la classe de risque maximum, $8 \mathrm{~km}$ à la classe de risque moyen, et $16 \mathrm{~km}$ à la classe de risque faible (Fig. 23). Les $87 \mathrm{~km}$ restants représentent un risque négligeable (Cuisance \& de La Rocque, 1998).

\section{- Validation}

La pertinence de ces résultats a été validée par les données de PCR obtenus chez les glossines capturées lors

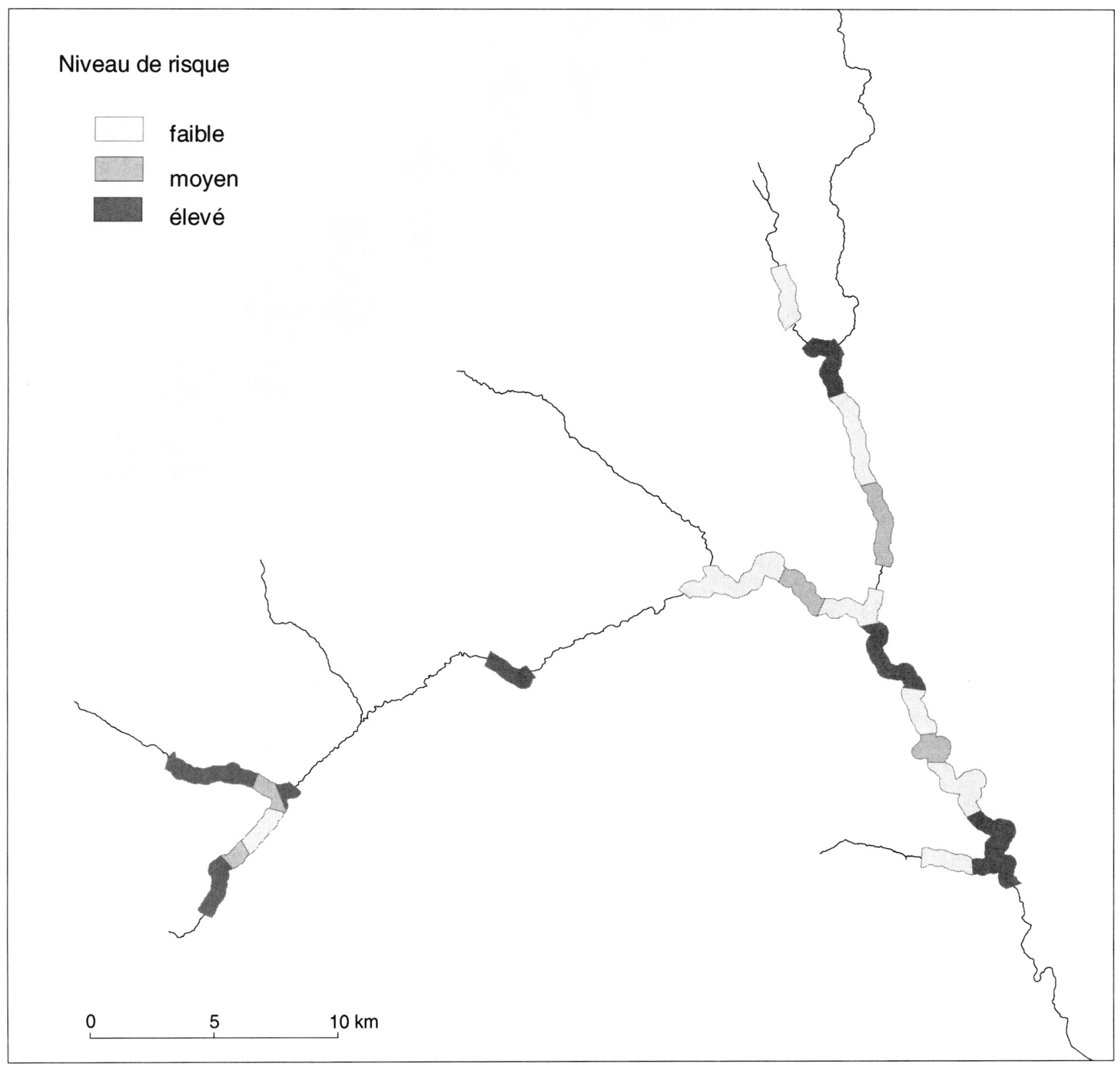

Fig. 23. - Localisation des zones épidémiologiquement dangereuses. 


\begin{tabular}{lccrc}
\hline Niveau de risque & Faible & Moyen & Êlevé & Négligeable \\
\hline T. vivax & 3 & 7,3 & 14,5 & 2,6 \\
T. congolense & 4,5 & 4,2 & 9,3 & 3,3 \\
T. brucei & 1 & 1,6 & 3,3 & 1,5 \\
non identifiés & 4 & 1,6 & 1,6 & 5,4 \\
\hline
\end{tabular}

Tableau VIII. - Pourcentage de réactions PCR positives par rapport au nombre de glossines disséquées.

de la prospection (tableau VIII). Il apparaît que le pourcentage de glossines infectées par des trypanosomes pathogènes est, pour les trois espèces de parasites, d'autant plus important que la zone a été décrite comme dangereuse. A l'inverse, le taux de trypanosomes non identifiés est plus élevé dans les zones où le risque est considéré comme faible ou négligeable $(\mathrm{p}<0,01)$.

Les cartes des prévalences sérologiques et parasitologiques confirment également la liaison forte entre les zones de risque maximum et la présence de parasites ou d'anticorps chez les bovins. La fréquentation d'une zone à risque entraîne une augmentation d'un facteur 3 à 7 (selon la régularité de fréquentation) pour la prévalence sérologique et d'un facteur 3 à 4 pour la prévalence parasitologique.

Une lutte antivectorielle très ciblée sur ces points épidémiologiquement dangereux est actuellement en place. Des captures régulières de glossines et des suivis de troupeaux sentinelles permettront d'estimer son efficacité locale et son rayon d'influence.

\section{DISCUSSION}

\section{LES GLOSSINES VUES DU CIEL}

J usque dans les années 80, l'éradication des vecteurs a été considérée comme un objectif majeur pour supprimer les trypanosomoses animales en Afrique (Jordan, 1986). Les efforts se sont concentrés sur la cartographie des vecteurs, en particulier des glossines savanicoles dont l'impact économique est le plus important. Les cartes de références classiquement citées sont maintenant anciennes (Ford \& Katondo, 1977, Katondo, 1984) et il y a donc une demande pressante pour définir des indicateurs rapides, efficaces et généralisables de la présence des glossines.

L'influence des paramètres écologiques, notamment climatiques, sur la distribution et l'abondance des tsé-tsé a depuis longtemps été mis en évidence (Nash, 1937), et certaines variables intervenant dans la biologie et les dynamiques de population des glossines, comme la température, l'humidité, la pluviosité ou la couverture végétale peuvent être révélées par les capteurs embarqués sur des satellites. L'utilisation des données de télédétection a fait l'objet d'importantes recherches dans les dernières années (Hay, 1997; Allsopp, 1998; Kitron, 1998). Rogers \& Randolph les premiers ont associé des informations relevées au sol (disponibles dans les bases de données internationales) avec notamment le NDVI (Normalised Difference Vegetation Index) calculé à partir de données des satellites de la série NOAA pour prédire la présence au Kenya et en Tanzanie de Glossina pallidipes et G. morsitans avec respectivement une sensibilité de 79 et $84 \%$ (Rogers \& Randolph, 1993). En Afrique de l'Ouest, une approche similaire a été utilisée pour déterminer les limites de distribution de huit espèces de glossines en Côte d'Ivoire et au Burkina Faso (Rogers et al., 1996) et plus récemment six espèces au Togo (Hendrickx et al., 1999). En Afrique de l'Est, Robinson et al. ont comparé différentes techniques d'analyses univariées et multivariées appliquées à des données brutes de télédétection pour prédire la distribution de G. m. morsitans, G. m. centralis et $G$. pallidipes au Malawi, au Mozambique, en Zambie et au Zimbabwe avec une précision de 85 à $92 \%$ (Robinson et al., 1997; Robinson et al., 1997).

A ces échelles régionales ou nationales, les contrastes dans les paramètres éco-climatiques et les distributions entomologiques permettent de mettre en évidence des corrélations entre les deux domaines. Cependant les variables les plus discriminantes sont différentes non seulement selon les espèces de glossines, mais également selon les zones considérées, ce qui reflète la variabilité des situations et relativise les possibilités de généralisation. Les prévisions de distribution apparaissent sous une forme qualitative (présence ou absence des glossines). Avec certains satellites qui ont une fréquence de prise de vue élevée, le nombre élevé d'images disponibles peut permettre, à travers la caractérisation des cycles naturels durant l'année (par exemple de l'activité végétale) d'affiner les résultats, de mieux interpréter les données biologiques et de réaliser des prévisions sur l'abondance des insectes (Rogers et al., 1996).

De Wispelaere a été un des premiers à travailler sur la caractérisation des biotopes avec des images à haute résolution (De Wispeleare, 1994). Sur le plateau de l'Adamaoua, au Nord Cameroun, il a cherché à caractériser les habitats potentiels de Glossina morsitans submorsitans à partir de la physionomie de la végétation et l'occupation du sol révélées par le traitement d'images SPOT. L'auteur conclut que "la détection des gîtes potentiels ne peut être réalisée uniquement par une cartographie des formations ligneuses faite à l'aide de données satellitaires même à haute résolution. L'utilisation d'autres données exogènes à la télédétection est une nécessité". Cette contrainte constante de références aux données de terrain est une des caractéristiques (et une des limites) du travail à haute résolu- 
tion. De fait, plus la résolution est grande, plus les prévisions sont sensibles à la diversité du terrain.

Dans l'Ouest du Kenya, Kitron et al. ont associé des données à haute résolution $(30 \mathrm{~m})$ issues du satellite Landsat Thematic Mapper avec l'abondance de G. pallidipes (Kitron et al., 1996). À cette échelle, le NDVI est mal corrélé avec les densités, mais certaines données spectrales brutes, associées à l'humidité du sol et à la végétation, se sont révélées discriminantes. L'application de tests d'autocorrélation spatiale a cependant indiqué que les résultats obtenus d'un site de piégeage à l'autre ne sont pas indépendants, ce qui reflète l'influence d'autres facteurs que les seules données abiotiques (Davis et al., 1998) et demande des méthodes d'analyse géostatistiques complexes (Laffly \& Hervouët, 2000).

Lors du travail réalisé à Sidéradougou, la stratégie d'utilisation des outils de télédétection a été différente. Compte tenu de ces difficultés et de l'improbabilité, à une échelle aussi fine, d'obtenir suffisamment de contrastes dans les données brutes ou compilées issues de la télédétection, une approche plus naturaliste a été privilégiée, pour dans un premier temps décrire le milieu et dans un second temps définir des paysages qui correspondent à une réalité écologique pour les glossines. Si cette démarche ne permet pas de mettre en avant des variables directement fournies par les satellites, elle a en revanche débouché sur une meilleure compréhension des systèmes écologiques et épidémiologiques. Certains indicateurs forts mis en évidence, comme par exemple l'emprise agricole peuvent être retenus comme des éléments déterminants.

\section{ÉVOLUTION DES CONCEPTS D'APPRÉCIATION DU RISQUE}

Initialement, le concept de l'exposition au risque de trypanosomose était uniquement relié à l'abondance des glossines, mesurée par les densités apparentes. Plus tard, il a été affiné par la mise en place d'un indice de risque ou "challenge", estimé par le produit de deux paramètres déterminants, facilement mesurables sur le terrain : les densités des glossines non ténérales capturées par jour et les taux d'infections matures observées lors des dissections ((Whiteside, 1962; Murray et al., 1983; Leak et al., 1988). Cet indice a été amélioré en prenant en compte la nature des repas des glossines et les densités de bovins, ce qui correspond à une première considération des rapports hôtes-vecteurs (Snow \& Tarimo, 1983). Une relation linéaire entre le "challenge" et les incidences ou les prévalences parasitaires observées sur les bovins le ou les mois suivants a pu être mise en évidence (Leak et al., 1990; Rawlings et al., 1991; Leak et al., 1993). Des corrélations avec l'index Bérénil ont également été démontrées (Rogers, 1985), notamment en Gambie dans les zones infectées de Glossina morsitans submorsitans (Claxton et al., 1992). Cet indice a cependant été défini pour les situations où les glossines savanicoles dominent, et l'hétérogénéité de la répartition spatiale des vecteurs et des hôtes est souvent négligée (Wacher et al., 1993). Pour cette raison, il s'applique mal aux espèces riveraines, d'autant qu'il suppose que toutes les infections détectées sont liées à des parasites pathogènes. Les résultats obtenus ici montrent qu'à quelques kilomètres de distance et selon les paysages agro-écologiques, ces infections sont de nature diverse selon les types de contacts entre les vecteurs et les hôtes.

Plus tard, d'autres modèles mieux adaptés à la diversité des situations épidémiologiques ont été développés. Laveissière et al. ont défini un index de risque pour la trypanosomose humaine qui tient compte de la densité de mouche ténérales, du taux de survie des glossines et du contact entre les glossines et les hommes estimé par la fréquence de repas de sang d'origine humaine (Laveissière et al., 1994). Cet indice, qui reste calculable à partir des seules données entomologiques, intègre un grand nombre de paramètres qui varient selon les situations locales. Il a été utilisé de manière efficace en Côte d'Ivoire et au Cameroun (Fournet et al., 1999; Laveissière et al., 1997). Dans le domaine vétérinaire, différents modèles de transmission de la trypanosomose animale ont été décrits (Milligan \& Baker, 1988; Rogers, 1988). Certains de leurs paramètres, comme les taux de mortalité, peuvent être reliés à des données issues de la télédétection (Rogers \& Randolph, 1991; Rogers \& Randolph, 1993), mais les auteurs reconnaissent là encore la difficulté de trouver des indicateurs stables au cours des saisons, et généralisables à diverses situations agro-écologiques.

A la différence de ces modèles quantitatifs, la méthodologie du travail réalisé à Sidéradougou repose sur une approche essentiellement géographique, où les différentes composantes intervenant dans le fonctionnement du système épidémiologique ont été recherchées, cartographiées et mises en relation sur la base de leur interface spatiale. Les descriptions fines ont permis de mettre en évidence des situations variables de transmission, selon des indicateurs spatiaux, par exemple la localisation des campements ou l'occupation du sol. Est alors apparue l'intime imbrication du système pathogène avec les systèmes agro-écologique et socio-économique, l'homme jouant dans ce contexte de forte pression anthropique un rôle déterminant dans l'équilibre entre les hôtes, les vecteurs et les parasites.

\section{CONCLUSION}

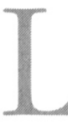

'originalité de ce travail a été d'appréhender de façon nouvelle, à la fois le système parasitaire luimême, mais aussi des facteurs agroécologiques 
(formations végétales, morphopédologie, hydrologie, paysages, etc.) et socio-économiques (occupation par l'homme, bétail, pratiques, gestion, etc.), qui entretiennent, exacerbent ou atténuent les risques de transmission des parasites aux hôtes. L'environnement au sens large n'est pas neutre dans les processus de maintien, d'émergence et de réémergence des trypanosomoses. Cette étude souligne la nécessité de bien connaître l'agent infectieux, mais aussi l'importance d'identifier des indicateurs de présence des vecteurs et de contact avec les hôtes afin qu'apparaissent les éléments explicatifs essentiels du fonctionnement épidémiologique dans un milieu donné, et que soient définis les paysages générateurs de risques. Cette démarche, appliquée ici aux glossines ripicoles, peut être étendue à d'autres maladies parasitaires liées à des vecteurs (comme les tiques ou divers diptères d'importance médicale), à des hôtes intermédiaires, ou même certaines pathologies à transmission directe.

Cette étude constitue aussi une étape de recherche appliquée, ancrée dans des problèmes concrets de développement. Dans la situation préoccupante de résurgence des trypanosomoses, la démarche de croisement de couches d'informations multi-thématiques a des chances d'apporter des explications supplémentaires à l'explosion de certains foyers, dont les causes restent encore mal définies. Dans le domaine des trypanosomoses animales, face à la raréfaction des financements disponibles, les indications d'intervention seront tributaires d'un diagnostic rapide de la situation, d'une estimation des risques et des priorités, et d'une évaluation des contraintes, des ressources et des potentialités. L'enjeu est donc de mettre en évidence des indicateurs robustes, fiables, et rapides à obtenir, en privilégiant les données de télédétection et les procédures standardisées. Différentes équipes travaillent actuellement vers cet objectif; elles sont très complémentaires notamment sur les échelles de description, qui vont du sous-continent au terroir (Hendrickx et al., 2001), mais impliquent de nouveaux développements méthodologiques pour qu'elles s'imbriquent plus efficacement

\section{REMERCIEMENTS}

L es auteurs remercient le Dr Saydil M. Touré, Directeur du CIRDES, et à travers lui le personnel 1 du CIRDES pour leur accueil et leur appui aux travaux de recherche. Ce projet a été réalisé grâce à un financement du CIRAD (Mission Production Animale, Action Thématique Programmée Santé-Environnement) et du CNRS (programme Environnement, Vies et Sociétés). Il a été récompensé du prix NovartisPharma de l'Académie Nationale de Médecine et du Prix Presson de la Société Entomologique de France.
L'ensemble de ces travaux seront détaillés dans un ouvrage actuellement à l'édition : de La Rocque S., Michel J.F., Cuisance D., De Wispeleare G., Augusseau X., Guillobez S. \& Arnaud M. Le risque trypanosomien, une approche globale pour une décision locale, 2001, sous presse. Édition du CIRAD, Montpellier, 152 p.

\section{RÉFÉRENCES}

AlLSOPp R. Geographic Information System (GIS) and remote sensing aid tsetse control in Botswana. Pesticide Oultlook, 1998, 9, 9-12.

Amat-Roze J.M. \& Gentilini M. La santé en carte. In: Penser la terre, stratège et citoyens, le réveil des géographes. Édition Autrement, Paris, 1995, 119-137.

Augusseau X., Pare S. \& Sare J.B. Caractérisation régionale de l'emprise agricole et de la dynamique dans une zone de migrations. Ouagadougou, Burkina Faso, avril 1998.

Borne F. Méthodes numériques de reconnaissances des paysages. Thèse Doctorat Sciences, Université Paris VII, France, 1989, $213 \mathrm{p}$.

ChAlliER A. Écologie de Glossina palpalis gambiensis Vanderplanck 1949 en savane d'Afrique Occidentale. Editions de l'ORSTOM, Montpellier, 1973, 274 p.

Challier A. \& LAveissière C. Un nouveau piège pour la capture des glossines (Glossina: Diptera-Muscidae), description et essais sur le terrain. Cabier de l'ORSTOM, Série Entomologie médicale et Parasitologie, 1973, XI, 251-262.

Chartier C., Itard J., Morel P.C. \& Troncy P.M. Précis de parasitologie tropicale. AUPELF-UFEF, Éditions TEC et DOC, 2000, 774 p.

Clausen P.H., Adeyemi I., Bauer B., Breloeer M., Salchow F. \& STAAK C. Host preferences of tsetse (Diptera: Glossinidae) based on bloodmeal identifications. Medical and Veterinary Entomology, 1998, 12, 169-180.

Claxton J.R., Leperre P., Rawlings W.F., Snow W.F. \& DwINGER R.H. Trypanosomiasis in cattle in Gambia: incidence, prevalence and tsetse challenge. Acta Tropica, 1992, 50, 219-225.

Cuisance D., Barre N. \& De Deken R. Ectoparasites des animaux : méthodes de lutte écologique, biologique, génétique et mécanique. Revue scientifique et technique de l'Office international des Epizooties, 1994, 13, 1305-1356.

Cuisance D. \& DE La Rocque S. Tsé-tsé et trypanosomoses. Du système pathogène à l'évaluation du risque. CIRADEMVT/CNRS, Montpellier, 1998.

Cuisance D., Politzar H., Tamboura I., Merot P. \& LamarQUE G. Répartition des glossines dans la zone pastorale d'accueil de Sidéradougou, Burkina Faso. Revue d'Élevage et de Médecine vétérinaire des Pays tropicaux, 1984, 37, 99-113.

D'Amico F. Rôle de Glossina fuscipes fuscipes Wewstead, 1910, dans la transmission des trypanosomoses bovines en Afrique centrale. Cas de la zone d'élevage d'Ouro-Djafoun (République centrafricaine). Thèse Doctorat Sciences, Université Montpellier II, France, 1993, 160 p. 
Davis A.J., Jenkinson L.S., Lawton J.H., SHOrRocks B. \& WooD S. Making mistakes when predicting shift in species range in response to global warming. Nature, 1998, 391, 783-786.

DE LA ROCQUE S. Identification des facteurs discriminants de la présence de glossines dans une zone agro-pastorale du Burkina Faso. Intérêt pour l'évaluation du risque trypanosomien. Thèse Doctorat Sciences, Université Montpellier II, France, 1997, 162 p.

de La Rocque S., Bengaly Z., Michel J.F., Solano P., Sidibé I. \& CUISANCE D. Importance spatiale et temporelle des interfaces bovins-glossines dans la transmission de la trypanosomose animale en Afrique de l'Ouest. Revue d'Élevage et de Médecine vétérinaire des Pays tropicaux, 1999, 52, 215-222.

De la Rocque S., Augusseau X., Guillobez S., Michel V., De Wispelaere G., Bauer B. \& Cuisance D. The changing distribution of two riverine tsetse flies over 15 years in an area increasingly occupied by agriculture in Burkina Faso. Bulletin of Entomological Research, 2001a, 91, 157-166.

de La Rocque S., Michel J.F., Cuisance D., De Wispeleare G., Augusseau X., Guillobez S. \& Arnaud M. Le risque trypanosomien, une approche globale pour une décision locale, 2001b, sous presse. Édition du CIRAD, Montpellier, 152 p.

DE Wispeleare G. Contribution of satellite remote sensing to the mapping of potential Glossina biotopes. Case study of the Adamawa plateaux in Cameroon. FAO Animal Production and Health Paper, 1994, 121, 74-89.

Desquesnes M., Michel J.F., de La Rocque S., Solano P., MilLOOGO L., Sidibé I. \& CuisAnCE D. Enquête parasitologique et sérologique (ELISA-indirectes) sur les trypanosomoses des bovins dans la zone de Sidéradougou, Burkina Faso. Revue d'Elevage et de Médecine Vétérinaire des pays Tropicaux, 1999, 52 (3-4), 223-232.

FAO. The Coordination of research and development within a global program to clarify and solve the problem of African animal trypanosomiasis. 22-25 novembre 1994, Vienne, 1994.

FORD J. \& KATONDO K.M. Maps of tsetse flies (Glossina) distribution in Africa, 1973, according to sub-generic groups on scale of 1: 5.000 .000 (plus a set of 9 maps in colour). Bulletin of Animal Health, Prod. Afr., 1977, 2, 187-193.

Fournet F., Koné A., Traoré S. \& Hervouët J.P. Heterogeneity in the risk of sleeping sickness in coffee and cocoa commercial plantation in Côte d'Ivoire. Medical and Veterinary Entomology, 1999, 13, 333-335.

Frezil J.L., Eouzan J.P., Alary J.C., MalOnga J.R. \& GinOuX P.Y. Épidémiologie de la trypanosomiase humaine en République populaire du Congo. Cahiers de l'ORSTOM, Série Entomologie médicale et Parasitologie, 1980, XVIII, 329-346.

Gruvel J. Contribution à l'étude écologique de Glossina tachinoides Westwood 1850 (Diptera : Muscidae) dans la réserve de Kalamaloué, vallée du Bas Chari. Thèse Doctorat Sciences Naturelles, Université Paris VI, France, 1974, $303 \mathrm{p}$.

HAY S.I. Remote sensing and disease control: past, present and future. Transaction of the Royal Society of tropical Medicine and Hygiene, 1997, 91, 105-106.
Hendrickx G., De La Rocque S., ReID R. \& Wint W. Spatial trypanosomosis management: from data-layers to decision making. Parasitology Today, 2001, 17, 35-41.

Hendrickx G., Napala A., Dao B., Batawui D., De Deken R., VERMEILEN A. \& SLINGENBERgh J.H.W. A systematic approach to area-wide tsetse distribution and abundance maps. Bulletin of Entomological Research, 1999, 89, 231-244.

Hursey B.S. \& Slingenbergh J. The tsetse fly and its effects on agriculture in sub-Saharian Africa. Revue Mondiale de Zootechnie, 1995, 84, 67-73.

ITARD J. Les glossines ou mouches tsé-tsé. Éditions de l'IEMVT, Maisons-Alfort, 1986, 155 p.

JORDAN A.M. Trypanosomiasis control and african rural development. Longman Editions, London, 1986, 357 p

KAISER B. A quantification of texture on aerial photographs. Boston University Research Laboratories, Technical note $n^{\circ} 121,1995$

KATONDO K.M. Revision of second edition of tsetse distribution maps. Insect Science and its Applications, 1984, 5, 381388.

KITRON U. Landscape ecology and epidemiology of vectorborne disease: tools for spatial analysis. Journal of Medical Entomology, 1998, 35, 435-445.

Kitron U., Otieno L.H., Hungerford L.L., Odulaja A., Brigham W.U., OKello O.O., Joselyn M., Mohamed-Ahmed M.M. \& Cook E. Spatial analysis of the distribution of tsetse flies in the Lambwe Valley, Kenya, using Landsat TM satellite imagery and GIS. Journal of Animal Ecology, 1996, 65, 371380.

LAFFly D. \& Hervouët J.P. Une mouche tsé-tsé dans le capteur! Identification de facteurs de risque de la THA par télédétection et analyse spatiale. In : Maladies émergentes et reviviscentes. Espace, Population, Société, 2000, 2, 227239.

LAMBRECHT F.L. Ecological and physiological factors in the cyclic transmission of African Trypanosomiasis. Insect Science and its Applications, 1980, 1, 47-54.

LANDAIS E. Analyse des systèmes d'élevage sédentaires du nord de la Côte d'Ivoire. IEMVT-CIRAD, Maisons-Alfort, 1983, 759 p.

LAVEIssière C. \& Boreham P.F.L. Écologie de Glossina tachinoides Westwood, 1850, en savane humide d'Afrique de l'Ouest. I. Préférences trophiques. Cahiers de l'ORSTOM, Série Entomologie médicale et Parasitologie, 1976, XIV, 187200.

LAVEISSIÈRE C. \& COURET D. Lutte contre les glossines riveraines à l'aide de pièges biconiques imprégnés d'insecticide, en zone de savane humide. I. Description du lieu, du matériel et de la méthode. Cahiers de l'ORSTOM, Série Entomologie médicale et Parasitologie, 1980, XVIII, 201207.

Laveissière C., Couret D. \& Hervouët J.P. Localisation et fréquence du contact homme-glossines en secteur forestier de Côte d'Ivoire. I. Recherche des points épidémiologiquement dangereux dans l'environnement végétal. Cahiers de l'ORSTOM, Série Entomologie médicale et Parasitologie, 1986, XXIV, 21-35. 
Laveissière C., Sane B., Diallo P.B., Truc P. \& Méda A.H. Le risque épidémiologique dans un foyer de maladie du sommeil en Côte d'Ivoire. Tropical Medicine and International Health, 1997, 2, 729-732.

Laveissière C., SAné B. \& MÉda H.A. Measurement of risk in endemic areas of human African trypanosomiasis in Côte d'Ivoire. Transaction of the Royal Society of Tropical Medicine and Hygiene, 1994, 88, 645-648.

Leak S.A.G., Awuome K., Collardelle C., Duffera W., Feron A., Mahamet B., Mawuena K., Mulogo M., Nankodaba G., Ordner G., Pelo M., Sheria M., Tikubet G., Touré M. \& YANGARI G. Determination of tsetse challenge and its relationship with trypanosome prevalence in trypaotolerant livestock at sites of the African Trypanotolerant Network. In: Livestock production in tsetse affected areas of Africa. Proceedings of a meeting held 23-27 November 1987, Nairobi, Kenya, 1988.

Leak S.A.G., Collardelle C., Coulibaly C., Dumont P., Feron A., Hecker P., D'Ieteren G.D., Jeannin P., Minengu M., Minja S., Mulatu W., Nankodaba G., Ordner G., Rowlands G.J., Sauveroche B., Tikubet G. \& Trial J.C.M. Relationship between tsetse challenge and trypanosome prevalence in trypanotolerant and susceptible cattle. Insect Science and its Application, 1990, 11, 293-299.

Leak S.G.A., Mulatu W., Authié E., D'Ieteren G.D.M., PereGRINe A.S., Rowlands G.J. \& Trail J.C.M. Epidemiology of bovine trypanosomiasis in the Ghibe Valley, southern Ethiopia. 1. Tsetse challenge and its relationship to trypanosome prevalence in cattle. Acta Tropica, 1993, 53, 121-134

Lefrançois T., Solano P., de la Rocque S., Bengaly Z., ReIfenberg J.M., Kabore I. \& Cuisance D. New epidemiological data on animal trypanosomosis by molecular analysis in the pastoral zone of Sidéradougou, Burkina Faso. Molecular Ecology, 1998, 7, 897-904.

Lhoste P., Dolle V., Rousseau J. \& Soltner D. Manuel de zootechnie des régions chaudes : les systèmes d'élevage. Ministère de la Coopération, Paris, 1993, 288 p.

McNamara J.J., Laveissière C. \& Masiga D.K. Multiple trypanosome infections in wild tsetse in Côte d'Ivoire detected by PCR analysis and DNA probes. Acta Tropica, 1995, 59, $85-92$.

Michel J.F., Michel V., De La Rocque S., Touré I. \& Richard D. Modélisation de l'occupation de l'espace par les bovins. Applications à l'épidémiologie des trypanosomoses animales. Revue d'Élevage et de Médecine vétérinaire des Pays tropicaux, 1999, 52, 25-33.

Michel J.F., Dray S., de la Roceue S., De Wispelaere G., DesQuesnes M., Solano P. \& Cuisance D. Modelling bovine trypanosomosis spatial distribution by GIS in an agro-pastoral zone of Burkina Faso. Prev. Med. Vet. Accepté.

Milligan P.M.J. \& BAKER R.D. A modele of tsetse-transmitted animal trypanosomiasis. Parasitology, 1988, 96, 211-239.

Murray M., Murray P.K. \& McInTyre W.I.M. An improved parasitological technique for the diagnosis of african trypanosomiasis. Transactions of the Royal Society of Tropical Medicine and Hygiene, 1977, 71, 325-326.
Murray M., Trail J.C.M., Turner D.A. \& Wissoque I. Livestock productivity and trypanotolerance training manual. Centre International pour l'Élevage en Afrique, Addis Abeba, Éthopie, 1983, 230 p.

NASH T.A.M. Climate, the vital factor in the ecology of Glossina. Bulletin of Entomological Research, 1937, 28, 75-127.

Picheral H. Complexes et systèmes pathogènes: approche géographique. In: De l'épidémiologie à la géographie humaine, Doumergue C.C. (éd.), Travaux \& Documents, Talence, 1982, 48, 5-21.

Rawlings P., Dwinger R.H. \& Snow W.F. An analysis of survey measurement of tsetse challenge to trypanotolerant cattle in relation to aspect of analytical models of trypanosomiasis. Parasitology, 1991, 102, 371-377.

Reifenberg J.M., Solano P., Bauer B., Kabore I., Cuny G., Duvallet G. \& Cuisance D. Apport de la technique PCR pour une meilleure compréhension de l'épizootiologie des trypanosomoses bovines : exemple de la zone d'amenagement de Yalé au Burkina Faso. Revue d'Élevage et de Médecine vétérinaire des Pays tropicaux, 1997, 50, 14-22.

Robinson T., Rogers D. \& Brian W. Mapping tsetse habitat suitability in the common fly belt of Southern Africa using multivariate analysis of climate and remotely sensed vegetation data. Medical and Veterinary Entomology, 1997, $11,235-245$.

Robinson T., Rogers D. \& Williams B.G. Univariate analysis of tsetse habitat in the common fly belt of Southern Africa using of climate and remotely sensed vegetation data. Medical and Veterinary Entomology, 1997, 11, 223-234.

Rogers D.J. Trypanosomiasis "risk" or "challenge": a review. Acta Tropica, 1985, 42, 5-32.

Rogers D.J. A general model for African Trypanosomiasis. Parasitology, 1988, 10, 193-212.

Rogers D.J., Hay S.I. \& Packer M.J. Predicting the distribution of tsetse flies in West Africa using temporal Fourierprocessed meteorological-satellite data. Annals of Tropical Medicine and Parasitology, 1996, 90, 225-241.

Rogers D.J. \& RANDOlPh S.E. Mortality rate and population density of tsetse flies correlated with satellite imagery. Nature, 1991, 351, 739-741.

Rogers D.J. \& Randolph S.E. Distribution of tsetse and ticks in Africa: past, present and future. Parasitology Today, 1993, 9, 226-271.

Rougerie G. \& Beroutchachvili N. Géosystèmes et paysages. Bilan et méthodes. Armand Colin, Paris, 1991, 302 p.

SLINGENBERGH J. \& WINT W. Livestock geography and land use. Conférence Internationale Élevage et Environnement, 1620 juin 1997, Wageningen, Pays-Bas, 1997, 13 p.

SNOW W.F. \& TARIMO S.A. A quantification of the risk of trypanosomiasis infection to cattle on the south Kenya coast. Acta Tropica, 1983, 40, 331-340.

Solano P., Argiro L., Reifenberg J. M., Yao Y. \& Duvallet G. Field application of the Polymerase Chain Reaction (PCR) to the detection and characterization of trypanosomes in Glossina longipalpis in Côte d'Ivoire. Molecular Ecology, 1995, 4, 781-785. 
Solano P., Michel J.F., Lefrançois T., de La Rocque S., Sidibe I., Zoungrana A. \& Cuisance D. Polymerase chain reaction as a diagnosis tool for detecting trypanosomes in naturally infected cattle in Burkina Faso. Veterinary Parasitology, 1999, 86, 95-103.

Solano P., Reifenberg J.M., Amsler-Delafosse S., Kabore I., CuiSAnce D. \& Duvallet G. Trypanosome characterization by polymerase chain reaction in Glossina palpalis gambiensis and $G$. tachinoides from Burkina Faso. Medical and Veterinary Entomology, 1996, 10, 354-358.

Toutain B., Dumas R. \& Tacher G. Zone pastorale d'accueil de Sidéradougou (Haute Volta). Étude préliminaire. IEMVT, Maisons-Alfort, France, 1978

UilenBERG G. A field guide for the diagnosis, treatment and prevention ot african animal trypanosomosis. FAO, Rome, 1998, 158 p.

Wacher T.J., Milligan P.J. M., Rawlings P. \& SnOW W.F. Tsetse-trypanosomiasis challenge to village N'Dama cattle in the Gambia: field assessment of spatial and temporal patterns of tsetse-cattle contact and the risk of trypanosomiasis infection. Parasitology, 1994, 109, 149-162.

WaCher T.J., Rawlings P. \& SNOW W.F. Cattle migration and stocking densities in relation to tsetse-trypanosomiasis challenge in The Gambia. Annals of Tropical Medicine and Parasitology, 1993, 87, 517-524.

WHITESIDE E.F. Interaction between drugs, trypanosomes and cattle in the field. In: Drug, parasites and hosts. Whiteside: ed. L.G. Godwin and R.H. Nimmo-Smith, London, J. \& A. Churchill Ltd., 1962, 117 p.

WINT W. \& Bourn D. Anthropogenic and environmental correlates of livestock distribution in Sub-Saharian Africa. A comparative analysis of livestock surveys in Mali, Niger, Nigeria, Sudan and Tchad. The Overseas Development Administration, London, 1994.

Reçu le 7 février 2001

Accepté le 14 juin 2001 